\title{
Hyaluronan - a functional and structural sweet spot in the tissue microenvironment
}

\author{
James Monslow, Priya Govindaraju and Ellen Puré* \\ Department of Biomedical Sciences, University of Pennsylvania, Philadelphia, PA, USA
}

Transition from homeostatic to reactive matrix remodeling is a fundamental adaptive tissue response to injury, inflammatory disease, fibrosis, and cancer. Alterations in architecture, physical properties, and matrix composition result in changes in biomechanical and biochemical cellular signaling. The dynamics of pericellular and extracellular matrices, including matrix protein, proteoglycan, and glycosaminoglycan modification are continually emerging as essential regulatory mechanisms underlying cellular and tissue function. Nevertheless, the impact of matrix organization on inflammation and immunity in particular and the consequent effects on tissue healing and disease outcome are arguably under-

OPEN ACCESS

Edited by:

David Naor,

Hebrew University of Jerusalem, Israel

Reviewed by:

Alberto Passi,

Università degli Studi dell'Insubria,

Linda M. Pilars

Italy

University of Alberta, Canada

${ }^{*}$ Correspondence: Ellen Puré,

Department of Biomedical Sciences, University of Pennsylvania, $380 \mathrm{~S}$.

University Avenue, Philadelphia, PA 19104, USA

epure@vet.upenn.edu

Specialty section:

This article was submitted to Inflammation, a section of the journal

Frontiers in Immunology

Received: 15 February 2015 Accepted: 29 April 2015

Published: 15 May 2015

Citation:

Monslow J, Govindaraju $P$ and Puré

$E$ (2015) Hyaluronan - a functional and structural sweet spot in the tissue microenvironment.

Front. Immunol. 6:231. doi: 10.3389/fimmu.2015.00231 studied aspects of adaptive stress responses. Herein, we review how the predominant glycosaminoglycan hyaluronan $(\mathrm{HA})$ contributes to the structure and function of the tissue microenvironment. Specifically, we examine the evidence of HA degradation and the generation of biologically active smaller $\mathrm{HA}$ fragments in pathological settings in vivo. We discuss how HA fragments versus nascent HA via alternate receptor-mediated signaling influence inflammatory cell recruitment and differentiation, resident cell activation, as well as tumor growth, survival, and metastasis. Finally, we discuss how HA fragmentation impacts restoration of normal tissue function and pathological outcomes in disease.

Keywords: hyaluronan, remodeling, matrix, homeostasis, pathogenesis

\section{Introduction}

In the 80 years that have passed since hyaluronan (HA - also known as hyaluronic acid or hyaluronate) was first isolated and purified from the vitreous humor of the eye (1), the perception of this structurally seemingly simple molecule has changed dramatically. From simple beginnings, and being thought of merely as a "space-filler," our understanding of its role grew slowly at first, steadily gathered steam and has now entered its exponential phase. HA is now recognized as a molecular powerhouse with critical roles in homeostasis, pathological disease onset, progression, and recovery or decline. This is none more so evident than in the number of review articles of which the biological role of HA has been the focus over the last few years alone [2012-2014 nearly 40 reviews, including an entire edition dedicated to its role in cancer (2)]. It is well established that native HA matrix found in homeostasis plays important biomechanical and biophysical roles as a hydrated cushioning agent and/or molecular filter in connective tissue, joints, and skin $(3,4)$. Furthermore, increased HA accumulation is a hallmark of almost all diseases in which inflammation and/or fibrosis occur, especially tumor growth and metastasis (2, 4-10). Importantly, HA polymer length (and thus its molecular weight, MW) plays a significant part in the nature of its interactions with the extracellular matrix (ECM), cell surface receptors (including its major receptor, CD44) on both 
resident and recruited cells, and influences how cells in tissue respond to extracellular cues under these conditions (4, 10-15). The existing literature clearly pinpoints that the MW characteristics of HA are important determinants of its biological activity, through in vitro and in vivo studies describing how exogenously added HA of different MW affects cellular signaling and function $(4,8,11,12,16-19)$. There, however, has been limited work to elucidate the distribution of varying sizes of endogenous HA in the tissue in question, the alterations to HA MW that occur during disease progression and how these HA fragments change the biomechanical and biophysical properties of the tissue in vivo. Nor have many of the reports where exogenous HA was added, elucidated how this effected the size distribution of endogenous $\mathrm{HA}$, and over time, its effects on tissue architecture and cellular signaling that translate to either recovery of homeostasis or progression of disease. This is especially important in the context of cancer progression, as the effects of altering HA MW may have varying and opposing effects depending on the origin of the cancer, the tissue in which it resides, and the stage of the disease (20). The recent findings in the naked mole rat that suggest a link between the animals' resistance to cancer and the extraordinarily high MW (HWA) HA in its tissues have brought this subject into the limelight (21). For the above reasons, we have confined this review to focus on (i) a summary of the existing knowledge about HA MW distribution in vivo under homeostasis and disease, (ii) mechanisms responsible for alterations in HA MW and the occurrence of these mechanisms in pathological settings, and (iii) the opposing effects of HMW-HA versus HA fragments on ECM function, receptor-mediated cellular signaling and disease outcome.

\section{HA Molecular Weight Distribution in Homeostasis and Disease}

\section{HA Molecular Weight - Why Do We Care?}

Hyaluronan is a polysaccharide of repeating units of D-glucuronic acid and $N$-acetyl-glucosamine. This highly charged, hydrophilic molecule is among the largest polysaccharides in nature, and in mammals one of the simplest with regards to structure. It is the major, non-proteinaceous component of the ECM, structurally distinct from other glycosaminoglycans (GAGs) in that it is unmodified (i.e., non-sulfated) and linear [non-branching (22)]. In its most common, homeostatic, and native form, HA polymer chain length exists as a HMW molecule, with sizes commonly above $1000 \mathrm{kDa}$. In this form, HMW-HA possesses biophysical properties that serve as a lubricant to hydrate tissue and create a matrix that sequesters growth factors and cytokines (23). It is uniquely synthesized at the plasma membrane with the completed polymer extruded to the extracellular space by the hyaluronan synthase enzymes (HASs). Increased HAS synthesis and HA accumulation are hallmarks of many pathological conditions (24). HMW-HA is degraded in vivo by hyaluronidases (Hyals), a family of enzymes that hydrolyze HA chains into intermediate (medium MW, MMW) or short (low MW, LMW) fragments (18). Changes in HA synthesis and degradation in part mediate the biochemical and rheological alterations to reactive matrices that occur during disease progression. Under certain pathological conditions, the extent of HA fragmentation is greatly enhanced, causing significant changes in the distribution and size of biologically active HA products, including the accumulation of HA oligomers $[<10 \mathrm{kDa}$ or $<20$ monomers - oligo-HA $(25,26)]$. Collectively, these bioactive HA fragments serve to interact with cells and influence behavior in different ways to HMW-HA (27-31).

\section{HA MW Distribution in Health Versus Disease - It is the Small (HA) Things that Matter}

A correlation of increased HA levels in the pathological setting is now par for the course. However, understanding the MW distribution of HA in vivo, how it varies between different tissues, and how the ratio of HMW-, MMW-, LMW-, and oligo-HA changes during disease progression is also paramount when developing treatment regimens that target HA. Surprisingly, measurements of HA MW distribution in vivo have only occasionally been investigated; these are summarized in Table S1 in Supplementary Material.

Upon review of the literature, it became clear that there was no consensus for what was termed HMW- versus MMW-, LMW- and oligo-HA. To better understand and compare the roles of HA of different sizes under various biological settings going forward, we, for the purpose of this review, categorize the various MW forms of HA as follows; HMW-HA (>1000 kDa), MMW-HA (250$1000 \mathrm{kDa})$, LMW-HA $(10-250 \mathrm{kDa})$, and oligo-HA $(<10 \mathrm{kDa})$. These groups are by no means distinctly distributed; in many settings, HA MW is polydisperse, encompassing more than one size category. In contrast, specific properties of HA are in certain instances associated with a defined and narrow spectrum of its MW (12).

A total of 65 studies reported analysis of HA MW in an array of tissues including skin, brain, eye, prostate, blood, circulating leukocytes, synovial tissue and fluid, cartilage, amniotic fluid, lymphatics, kidney, aorta, gums, lung and lung fluid, heart, larynx, liver, cervix, skeletal muscle, and urine across a variety of species (see Table S1 in Supplementary Material for references). Nineteen of the studies analyzed HA MW under homeostatic conditions exclusively. Surprisingly, we only found eight studies that analyzed HA in the context of cancer. The remaining studies reported HA size in a number of pathological settings, including cardiovascular disease (atherosclerosis and vascular injury), arthritis (rheumatoid and osteoarthritis), liver disease (septic shock and chronic liver fibrosis), vanishing white matter disease, skeletal ischemia, lung disease (asphyxia, cigarette smoke exposure, asthma, fibrosis, ischemia, and hypertension), skin wounding/healing, kidney disease, development, pregnancy, inflammation, and aging. HA exists in a HMW form under homeostatic conditions in almost all of the tissues where it was analyzed, with subtle yet possibly significant differences depending on the tissue and species (1000-7000 kDa). Notably, increased HA fragmentation was evident under pathological conditions, occurring in both inflammatory and fibrotic diseases. HA MW analysis in lung and skin pathologies had been more extensively analyzed compared to other tissues. A small amount of HA was detected in lungs under homeostatic conditions, found predominantly in the HMW form. Following insult or injury, a dramatic increase in total HA as well as fragmentation yielding LMW-HA species was observed. 
Comparatively, under homeostatic conditions, skin contained a greater amount of HA, though still present in a HMW form. Following injury (by wounding or exposure to UVB radiation), HA was detected in either a LMW or MMW form (ranging from 100 to $350 \mathrm{kDa}$ ). As wounds healed, HA MW gradually transitioned back to its native HMW form after 28 weeks. Two reports analyzed the effects of aging in the context of wound healing and found decreased Hyal activity and delayed wound repair and restoration of HMW-HA in aged animals (mouse and rat). HA, HAS, and Hyal enzymes have been implicated in a variety of cancers. HA size has been reported in prostate, lung, brain, larynx, liver, colon, and urine (bladder) cancer. Increased HA fragmentation was observed in the prostate ( 1 of 2 reports), urine, larynx, brain tumor cyst fluid, and colon cancer compared to their normal counterparts, with no observed/reported change in MW distribution in lung or liver cancer. Interestingly, the presence of oligo-HA in vivo was only reported in five studies, two of which were under homeostatic conditions in the aorta and urine, one in the interstitial fluid of patients with colon cancer, and the remaining two studies in vascular tissue following injury. Collectively, such limited data, therefore, make it challenging to generalize and suggest how to manipulate HA with the goal of altering disease progression. Furthermore, changing HA MW in the milieu in one specific tissue may then not be translatable to the treatment of carcinogenesis and other pathological settings in different tissues.

\section{Physiologic and Pathophysiologic Mechanisms of HA MW Modification In vivo}

\section{Is Synthesis Important?}

Accurate measurements of HA MW profiles may be in short supply, but there is a substantial body of work focusing on the molecular processes that govern HA MW and the methods by which HA fragments accumulate. Under normal homeostatic conditions HA metabolism is carefully controlled to maintain physiological concentration in tissues. Furthermore, changes in HA synthesis and/or degradation are hallmarks of an ongoing pathological process (32). The three mammalian HAS enzymes (HAS1-3) synthesize and secrete HA polymers of different length; HA secreted into the culture media by stable transfectants revealed that HAS1 makes MMW-to-HMW-HA (200-2000 kDa), whereas HAS2 is responsible for only HMW polymers $(>2000 \mathrm{kDa})$. HAS3 produces HA in the LMW-to-MMW range [100-1000 kDa (33)]. Stimuli such as cytokines [IL-1 $\beta$, TNF $\alpha$ (34-36), and IL-15 (37)] and growth factors [TGF- $\beta(36,38,39)$, PDGF $(39,40)$, HBEGF (41), and EGF (42)] can regulate HAS expression at the transcriptional level. Furthermore, HAS activity has more recently been shown to be controlled by direct phosphorylation $(43,44)$, O-GlcNAcylation (45), and ubiquitination (46). The availability of UDP-sugar precursors (constituents of the HA disaccharide subunit) is also a rate-limiting step for HA production (47). HAS2 also has a natural antisense transcript at its gene locus (HAS-AS1) that can stabilize HAS2 mRNA (48).

Collectively, there are, therefore, many cellular mechanisms that can regulate HA levels in tissue at the stage of synthesis. However, there is currently no evidence suggesting that any of these factors, or others, alter the ability of the HAS enzymes to modify the length of HA polymer they produce. HA MW distribution, and specifically the accumulation of smaller polymers, appears to lie solely in mechanisms specifically controlling its degradation, with HAS enzymes only able to replenish existing extracellular HA reservoirs.

\section{HA Turnover, Catabolism, and the Control of HA Fragmentation}

Extracellular HA can exist in a number of distinct pools that may have implications for HA turnover in homeostasis. Furthermore, any changes in the processes involved in the transition of HA from one pool to another could potentially affect its biological roles in the surrounding tissue. First, HA is synthesized as a HMW polymer that is retained as a pericellular coat, via retention by the HAS enzymes or receptor-mediated binding of HA following release of nascent chains from the synthases. Alternatively, HA can be released from the pericellular matrix and incorporated as an integral component of the ECM. Some may also be released as a soluble form into interstitial fluids or the circulation. In each case, HA is subject to subsequent degradation and either internalized and recycled by the resident cells or removed via the lymph. Under homeostatic conditions, HA has a high turnover rate, with as much as one third degraded to LMW fragments and replaced, each day. Lymphatic vessels drain considerable amounts of HA via receptor-facilitated uptake (utilizing receptors such as HARE, LYVE-1, and layilin), after which it is predominantly cleared in the liver. A small proportion is cleared by the kidneys ( 10\%) and only $1-2 \%$ is excreted in the urine $(3,49,50)$. In tissues containing high amounts of native HA (skin, cartilage, and joints), a significant amount is degraded locally, by processes involving HYAL-mediated cleavage and receptor-aided internalization, via CD44 and RHAMM $(49,51,52)$.

Hyaluronan fragmentation can occur via enzymatic or nonenzymatic processes. Enzymatic cleavage of HA by Hyal involves the hydrolysis of $\beta-1-4$ linkages in the HA chain (13). Six genes for Hyals have been identified in the human genome (Hyal-1-4, PH-20, and HYALP1), although only five of these encode protein products (not HYALP1) and of which only four can catabolize HA [not Hyal-3 (49)]. Hyal-1 cleaves HA over a wide MW range, down to oligo-HA fragments of only four or six saccharides in length (53). In contrast, Hyal-2 appears to cleave polydisperse HMW-HA to $20 \mathrm{kDa}$ fragments (54), although the lower limit of HA size that Hyal-2 can digest is still unclear. Both intracellular (by Hyal-1) and extracellular (by Hyal-2) degradations of HMW-HA are CD44dependent (55). $\mathrm{PH}-20$ degrades polydisperse HA to oligo-HA (including HA disaccharides), but its expression is almost exclusively limited to sperm, where it degrades HA in the cumulus layer of oocytes to facilitate fertilization (56). Reactive oxygen/nitrogen species (ROS/RNS) are also capable of non-enzymatic HA depolymerization and fragmentation. This is a non-selective process, resulting in HA fragments of various lengths (57-60).

Under homeostatic conditions Hyal-1 is expressed in the major parenchymal organs, such as the liver, kidney, spleen, and heart, at low levels in lung, skeletal muscle, and placenta, and is also detectable in plasma and urine. In comparison, Hyal-2 is highly expressed in most tissues. Interestingly, neither isoform has been detected in the brain (13). Hyal-1 exists as a $56 \mathrm{kDa}$ glycoprotein 
present in tissues and plasma and as a proteolytically processed $45 \mathrm{kDa}$ form that is only found in plasma (12). Whether these two forms cleave HA to dissimilar fragments or have distinct preferences for HA polymers of different MWs remains to be elucidated. Hyal-1 is active at an acidic $\mathrm{pH}$ (53), suggesting that at a cellular level it may reside in lysosomal compartments. Hyal2 shares many of the characteristics associated with Hyal-1; it has a MW of $55 \mathrm{kDa}$, also exists as a proteolytically processed smaller form and is optimally active at an acidic $\mathrm{pH}$. In contrast, Hyal-2 contains a glycosylphosphatidylinositol (GPI) linkage, thus tethering it to plasma membrane surfaces. There is a consensus that Hyal-2 may also localize to lysosomes, although there is some conflicting evidence that suggests this may not be the case (12). It is also unclear if membrane-tethered Hyal-2 is involved in releasing cell-associated HA from the pericellular environment in order that it can be integrated into the ECM. Hyal-3 is somewhat of an anomaly; strong transcriptional expression has been detected in bone marrow, testes, and kidney, although no changes in HA accumulation were observed in Hyal-3-deficient mice (61). To date, no activity has been detected in vivo, although Hyal-3 may contribute to HA metabolism and fragmentation by altering the activity of Hyal-1 (62).

\section{Evidence for Hyal Expression, Activity, and Hyal- or ROS-Dependent HA Fragmentation During Disease Progression In Vivo}

Any augmentation to Hyal expression, activity, or receptormediated lymphatic drainage has the potential to result in the accumulation of smaller bioactive HA fragments in tissue, and this has proven to be a hallmark of a variety of pathological conditions in vivo. Indeed, the genetic disorder mucopolysaccharidosis IX arises due to a mutation of Hyal-1. This mutation attenuates the ability of the enzyme to degrade HA, resulting in increased levels of HA in plasma and elevated storage of mucopolysaccharide in lysosomes (63). Table S1 in Supplementary Material documents changes in HA MW distribution in a variety of biological settings, which in some instances have been correlated with, or arise as a result of alterations in Hyal content. This is certainly true in inflammatory disease; platelet-derived Hyal-2 increases the accumulation of HA fragments that in turn stimulate monocytic IL-6 and IL- 8 production and downstream inflammatory responses in the local milieu (64). Furthermore, human $\mathrm{CD} 14^{+}$monocytes from normal as well as myelomonocytic lineages from leukemia patients express Hyal on their cell surface, thereby possessing the potential to degrade $\mathrm{HA}$ in the circulation as well as upon their recruitment to sites of disease (65). Increased Hyal activity, together with increased levels of LMW-HA has been reported in highly inflammatory atheromatous plaques during cardiovascular disease (66). Diabetes also correlated with increased Hyal expression in vascular tissue, with increased HA fragmentation (67). Conversely, increased deposition of MMW-HMW-HA led to severe cardiac dysfunction in Hyal-2-deficient mice (68). A variety of lung disorders have been examined for correlations between Hyal levels and HA fragmentation. Hyal-1 expression is increased in a model of pulmonary hypertension leading to accumulation of HA fragments (69). Airway smooth muscle cells from asthmatic or chronic obstructive pulmonary disease (COPD) patients have a reduction in average HA MW $(250 \mathrm{kDa})$ versus healthy controls
$(>700 \mathrm{kDa})$ that correlates with increased expression of Hyal1 (70). Furthermore, increased Hyal-2 expression, together with decreased HAS2 expression has been reported in patients with COPD (71). Generation of ROS, combined with increased Hyal2 activity also increases HA fragmentation (72). ROS-dependent HA fragmentation was also supported in two other separate studies, where exposure to cigarette smoke and subsequent ROS generation reduced pulmonary native $\mathrm{HA}(>500 \mathrm{kDa})$ to LMW$\mathrm{HA}[70 \mathrm{kDa}(73)]$, whereas pulmonary ischemia was associated with increased accumulation of LMW- and MMW-HA fragments [30-495 kDa (74)]. Interestingly, this latter study showed that HA fragmentation resulted solely from ROS activity, and not via Hyal degradation. In a model of skin injury, UVB irradiation of organotypic epidermal cultures induced Hyal, HAS, and CD44 expression, leading to an accumulation of LMW-HA fragments (75). HA fragmentation has also been recognized as a biological marker for rheumatoid arthritis (76). Indeed, TNF $\alpha$-stimulated synovial fibroblasts from arthritic mice show increased levels of LMW-HA (77).

Alterations in Hyal expression, activity, and HA fragmentation have also been reported in some oncogenic settings. Increased expression and activity of Hyal-1 and Hyal-2 were observed in a study of patients with colorectal cancer, with the highest activity found in the advanced stages of the disease (78). Overexpression of Hyal-1 also promoted mammary tumor growth and increased tumor angiogenesis (79). Increased Hyal activity together with the accumulation of HA fragments promoted pancreatic tumor cell motility (30), and the tumor cell line H460M (derived from human lung cancer) was also reported to produce high levels of Hyal, although not its own HA (80). Hyal expression has been found at elevated levels in other malignancies, including head and neck (81), prostate (82), brain (83), and urinary tract (84). Further reports suggest that increased Hyal levels might serve as a diagnostic marker for the onset and progression of bladder and epithelial ovarian cancer $(58,85,86)$. However, evidence exists that contradict these findings. A study of patients with endometrial cancer indicated that tumor tissues had elevated HA levels and correlated with lower expression of Hyal-1 and Hyal-2 compared to healthy controls (87). Decreased Hyal expression has also been reported in squamous cell head and neck carcinoma (88) as well as lung cancer (89). Furthermore, increased Hyal activity by genetic manipulation or intravenous administration suppressed tumor growth in models of colon and breast carcinoma, respectively $(90,91)$. In a separate study, ablation of HA in the tumor stroma by intravenous injection of Hyal decreased intratumoral fluid pressure and consequentially increased drug penetration in a model of pancreatic ductal carcinoma (92).

Collectively, current evidence suggests that HA synthesis and degradation are delicately balanced. The likelihood exists that alterations in either HA synthesis or degradation can have profound consequences on the other, which may account for opposing outcomes in disease progression. Indeed there is some evidence that supports this notion. Overexpression of HAS1 in prostate cancer was shown to be anti-tumorigenic; however, overexpression of both HAS1 and Hyal-1 increased HA fragmentation that in turn promoted tumor cell proliferation and metastasis (93). Furthermore, Hyal-1 expression in cancer cells themselves functioned as both a tumor promoter and tumor suppressor in 
prostate carcinoma (82). In a separate study in breast cancer, expression of antisense HAS2 (ASHAS2) increased accumulation of HMW-HA, while simultaneously causing the downregulation of Hyal-2. Combined, this inhibited the initiation and progression of primary and metastatic tumor progression (94).

\section{The Opposing Effects of Native HA versus HA Fragments on ECM Function, Receptor-Mediated Signaling, and Disease Outcome}

\section{HMW-HA - Keeping Tissues in Check?}

As discussed, HA in its native state is found in a HMW form $(>1000 \mathrm{kDa})$ that influences normal homeostatic functions in a variety of ways. HMW-HA has the ability to trap large amounts of water, thus possessing biophysical properties that serve to lubricate, hydrate, or space-fill tissues such as joints and connective tissue $(13,95)$. Its hydrophilic attributes also allow it to act as a molecular sieve and affect fluid absorption rates to and from tissue through changes in its concentration (96). HMW-HA possesses biomechanical properties, and none more so is this evident than during development. The maturing embryo is surrounded by a soft, hydrated matrix, rich in HMW-HA. Soft matrices are commonly considered to inhibit cellular adhesion and proliferation. Uniquely, the HA-rich microenvironment during development facilitates growth and development of tissues, including neuronal growth (97), limbs (98), blood vessels, and the heart (99). The presence of HMW-HA is critical to normal embryogenesis, as targeted deletion of HAS2 results in embryonic lethality, due to abnormal heart development (99). These distinct biomechanical properties of HA in soft tissue have recently been confirmed in vitro, where HA-rich soft substrates, as opposed to collagen-rich substrates of the same degree of stiffness but lacking HA, promoted cell spreading, focal adhesion and stress-fiber formation, and normal cell function (100). This might explain how embryonic cells are able to adhere, proliferate, and differentiate under soft conditions during development. It is interesting to speculate whether one may extend this hypothesis to wound healing; one of the first events in the formation of granulation tissue (for example in skin wounds) is an accumulation of HA in a soft fibrin matrix. The HA may serve to facilitate cell migration in the early stages of wound healing, prior to the onset of fibroproliferation, and the generation of a stiffer substratum as a result of increased matrix deposition. A HA-rich fibrin clot may enable swift tissue remodeling and healing in the face of initially soft conditions.

High molecular weight-HA-specific signaling has been shown to result in favorable outcome on cell and tissue function in adult tissues in response to environmental cues. In in vitro wound healing models, the incorporation of HMW-HA into collagen gels enhanced gel contraction, vascular smooth muscle cell (VSMC) cell spreading, filopodia formation, and pericellular accumulation of collagen fibers via the HA receptor CD44 (101). HMW-HA also promoted actin stress-fiber arrangement, lamellipodia formation, and cell migration (but not proliferation) in VSMCs (102). Inhibition of CD44 blocked HA-CD44-RhoA-mediated events, with the exception of migration, whereas inhibition of RHAMM (another $\mathrm{HA}$ receptor) and downstream Rac signaling only inhibited
HA-mediated migration (102). HMW-HA also enhanced myocardial repair when transplanted simultaneously with bone marrow mononuclear cells in the heart following myocardial infarction. The HMW-HA provided a favorable microenvironment for transplanted cell adhesion and proliferation, leading to reduced inflammation and cardiomyocyte apoptosis, as well as increased angiogenesis and cardiac performance (103). HMW-HA also increased CD44- and NF- $\mathrm{KB}$-dependent SNAIL2 expression leading to increased fibroblast invasion (104). Indeed, the role of HMW-HA in response to injury has been studied quite extensively. In the skin, HMW-HA improved permeability barrier function in aged epidermis via CD44-dependent mechanisms (105). This may in part be attributed to HMW-HA-CD44dependent mechanisms that control keratinocyte differentiation (106). HMW-HA also enhanced excisional wound contraction compared with saline-treated controls (107). In a diabetic woundhealing model, this was associated with enhanced angiogenesis, TGF- $\beta$, and transglutaminase II expression, restoration of cyclin B1/Cdc2 complex and increased mechanical strength (108). Independently, HMW-HA was shown to mitigate astrocyte activation in vitro and in vivo leading to a reduction in scarring (109). Furthermore, daily subcutaneous administration of a HMW-HA formulation (HYAL-BV 5200) inhibited neointimal formation and macrophage recruitment following balloon catheter-induced vascular injury in cholesterol-fed rabbits (110). Our group reported that the tissue response to vascular injury was CD44-dependent. HMW-HA inhibited mesenchymal cell cyclin D1 expression and subsequent cell proliferation via a CD44-dependent and Skp2dependent mechanism (111). HMW-HA may also control the response to injury by reducing VSMC apoptosis mediated via TLR4, CD44, and downstream PI3K signaling (112).

Many of the protective/healing effects associated with HMWHA in response to injury can be attributed to its suppressive effects on the inflammatory response. HMW-HA $(1600 \mathrm{kDa})$ completely blocked monocyte and neutrophil infiltration and MIP-2 and TNF $\alpha$ induction in a model of sepsis-induced lung injury, thus attenuating the injury response (113). T-cell-mediated liver injury, as well as the release of pro-inflammatory cytokines TNF $\alpha$, IFN $\gamma$, MIP2, and IL-4, was also inhibited by administration of HMWHA (114). HMW-HA increased SDF1b-induced CXCR4 signaling and cell motility, increased vessel sprouting, and angiogenesis. This process was again HA-CD44 dependent, with CD44 physically interacting with CXCR4 in the presence of the CXCL12 ligand (115).

High molecular weight-HA is also able to enhance immunosuppression via binding to the surface receptor TLR4 leading to an increase in the release of the immunosuppressive cytokine IL10 (116). Interestingly, this immunosuppressive effect has recently been suggested as a mechanism in infectious disease; HMW-HA impaired virus phagocytosis by macrophages and thus increased viral survival within the blood (117).

\section{HMW-HA and Cancer Progression}

The protective effect of HMW-HA is also evident in tumorigenesis. Treatment with HMW-HA inhibited post-chemotherapy tumor growth in a human colon carcinoma xenograft model in NSG mice (118). HMW-HA antagonized the pro-inflammatory 
effects of IL-1 $\beta$-treated chondrosarcoma cells, decreasing COX2, MMP-1, and MMP-13; promoting Akt; and suppressing MAPKs and NF- $\kappa B$ signaling, via PPAR $\gamma$-dependent signaling (119). HMW-HA also inhibited migration of fibrosarcoma cells. Interestingly, this effect was fibrosarcoma cell line-specific and did not occur in any of the other cancer cell lines that were tested (120). Conversely, overexpression of HAS2 (presumably leading to increased accumulation of HMW-HA) facilitated the reversion of cancer cells to a stem cell-like state via Twist and TGF- $\beta$ signaling and thus promoted tumor cell survival (121). It is, however, unclear if this survival was due directly to HMW-HA signaling, or due to further degradation of the accumulated HMW-HA and pro-oncogenic signaling as a result of an accumulation of HA fragments.

\section{Oligo-HA - the Gloves are Off}

Whereas evidence points to HMW-HA as protective and facilitating in the restoration of homeostasis in pathological settings, the effects of oligo-HA could not be more further removed. Many of the effects exerted by oligo-HA in pathological conditions occur via receptor-mediated signaling in immune cells leading to the promotion or protraction of inflammation. Oligo-HA induces the phenotypic maturation of human monocyte-derived dendritic cells (DCs) and the production of inflammatory cytokines IL-1 $\beta$, TNF $\alpha$, and IL-12. Interestingly this was not mediated via the HA receptors CD44 or RHAMM and was partly mediated indirectly via TNFR (122). Subsequently, DC maturation by oligo-HA was found to be mediated by its binding to TLR4 (and downstream p38/p42/44 MAP-kinase pathways). This was confirmed in vivo, as oligo-HA induced DC emigration from skin, as well as their phenotypic and functional maturation in the spleen (123). OligoHA administration to resting monocytes increases the expression of the scavenger receptor (CD36), uptake of oxidized LDL and their transendothelial migration. This particular response was CD44-dependent and mediated in part via the PKC pathway (124). Together, these data suggest that CD44 is directly implicated in prolonged inflammatory responses in many autoinflammatory conditions such as atherosclerosis. Furthermore, it suggests that CD44 may promote the conversion of macrophages to foam cells within lesions, leading to increased lesional lipid accumulation and immune cell content, conditions that favor lesion rupture, a risk factor for heart attack and stroke.

Oligo-HA receptor-mediated cell responses are not limited to the immune system. Endothelial cells (ECs) in particular are impacted by oligo-HA. Oligomers of 6,8 , and 10 disaccharides (but not 4 subunits) promoted EC proliferation and VEGF secretion (125). Increased EC proliferation in response to oligo-HA also increased tube formation, upregulation of the adhesion proteins ICAM and VCAM as well as the release of pro-inflammatory cytokines (126). In vivo, oligo-HA has been reported as one of the predominant mechanisms by which ECs respond to injury, with these responses mediated via oligo-HA-TLR4-dependent mechanisms (127). However, ECs also express ICAM and CD44, both of which can bind oligo-HA and potentially mediate cellular function $(128,129)$. Indeed, oligo-HA was shown to induce rapid upregulation of immediate-early genes c-fos, c-jun, junB Krox-20, and Krox-24, responsible for angiogenesis, in a
CD44-dependent manner. Additionally, immediate-early gene signaling was not sufficient to induce EC proliferation and was only induced upon long-term treatment with oligo-HA (129). Oligo-HA is also capable of inducing pro-inflammatory signals in chondrocytes. IL- $1 \beta$ treatment induced inflammatory signaling pathways that were mediated via oligo-HA-CD44 activation, leading to an increase in NF- $\kappa \mathrm{B}, \mathrm{TNF} \alpha$, IL-6, MMP-13, and iNOS, as well as the CD44 receptor itself (130).

A certain degree of inflammation and, therefore, the generation of some oligo-HA is a normal part of the body's response to insult. That being said, excess oligo-HA has often been shown to be detrimental to healing, causing protracted inflammation thus favoring disease progression. In contrast, the effects of oligoHA on resident mesenchymal cells suggest that it may facilitate tissue recovery and healing. Sustained delivery of oligo-HA by nano-particles increased elastin synthesis and lysl oxidase expression in rat SMCs to facilitate aortic remodeling following injury (131). Topical application of oligo-HA promoted keratinocyte proliferation and increased skin thickness and barrier function, in a CD44-dependent manner (105). Wound healing models have also revealed that administration of oligo-HA accelerates wound healing by promoting wound closure, the accumulation of M1 and M2 macrophages, release of TGF- $\beta$ (132), enhanced angiogenesis, lymphogenesis, and ECM deposition (133). OligoHA-accelerated wound closure was both CD44- and RHAMMdependent. Interestingly, although fibroblast proliferation was increased, myofibroblast differentiation within the granulation tissue did not change (132). Protective roles for oligo-HA have also been reported in cardiovascular disease. Together with TGF$\beta$, oligo-HA, but not larger HA polymers $(20,200$, or $2000 \mathrm{kDa})$, cooperatively enhanced elastin matrix regeneration in VSMCs (134), whereas oligo-HA administration protected against neointima formation in the aorta following balloon catheter injury in vivo (135). Oligo-HA can also upregulate hsp72 expression by enhancing the activation of HSF1 in response to hyperthermia in synovial cells, which acts as a protective mechanism by suppressing cell death (136). A separate recent study suggests a separate biochemical mechanism by which oligo-HA may facilitate healing. The covalent transfer of heavy chains (HCs) from inter$\alpha$-inhibitor ( $\mathrm{I} \alpha \mathrm{I})$ to HMW-HA via the protein product of tumor necrosis factor-stimulated gene-6 (TSG-6) forms a HC-HMWHA complex, a pathological form of HA that promotes the adhesion and retention of leukocytes to HA matrices (137). The transfer of $\mathrm{HCs}$ to HMW-HA is a reversible event mediated by TSG-6, whereas HC transfer to oligo-HA is irreversible. Treatment of HA-HC-rich synovial fluid from arthritic mice with oligo-HA and TSG-6 irreversibly shuttled HCs from pathological, HMW HC-HA to the oligo-HA. This suggests that oligo-HA could thereby facilitate the restoration of HA matrices in the inflamed joint to its normal, unmodified state, by removing HCs from HMW-HA, through more efficient clearance of HCs from tissue (138).

\section{Oligo-HA and Cancer Progression}

The current literature is divided upon whether oligo-HA (as well as LMW-MMW-HA as discussed later) promotes or suppresses tumor growth and metastasis. Complexities arise due to 
the wide and more varied effects that oligo-HA appears to have on tumors, compared to the effects it has on non-transformed cell types in other pathological conditions. This no doubt stems from the simple fact that tumors can develop in almost all tissues, from different cellular origins, and as a result of different mutations/environmental cues, to the point where you are in effect, looking at the role of one molecule (oligo-HA) on an ever increasing number of functionally and pathologically distinct, tumors. A number of these opposing effects are discussed below.

Oligo-HA induces CXCR7 expression in a TLR4-dependent manner, leading to the proliferation of W3 papillary thyroid carcinoma cells in vivo (28). In another independent study, oligoHA preferentially stimulated a physical association between CD44 with TLR2, TLR4 and the recruitment of MyD88 and actin filament-associated protein 110 (AFAP-110), leading to NF- $\kappa \mathrm{B}$ translocation and downstream expression of IL-1 $\beta$ and IL-8 in MDA-MB231 breast cancer cells. Combined, this promoted tumor cell invasion (139). Oligo-HA also upregulated the expression and acute phosphorylation of c-met, leading to proliferation, differentiation, and invasion of human chondrosarcoma cells. This effect was dependent on oligo-HA-CD44 interaction and signaling, and not observed with any other HA MW size (29). Similarly, oligoHA, but not LMW- or HMW-HA, induced MMP-9, -13, and uPAR in Lewis lung carcinoma (LLC) tumor cells, thus facilitating matrix remodeling and tumor cell migration. Interestingly, this response was not dependent on the interaction of HA with CD44, RHAMM, or TLR4 (140). More complex roles of oligo-HA with CD44 have also been reported in pancreatic carcinoma. OligoHA, generated by Hyal degradation, enhanced the cleavage of CD44 and its release into the ECM, which in turn enhanced tumor cell motility. This phenomenon was abrogated upon inhibition of HA-CD44 binding. This suggests that tumor cells enhance their own CD44 cleavage via Hyal activity and oligo-HA generation to promote their own motility, tumor invasion, and metastasis (30). In contrast, oligo-HA has the ability to kill many types of tumor cells by triggering apoptosis, while leaving normal cells unaffected. In an interesting extension of these findings, chemo-resistant tumor cells became drug-sensitive when treated in combination with oligo-HA (141). Indeed, this may be one mechanism by which oligo-HA inhibits the growth of B16F10 melanoma growth in vivo (142). This phenomenon has been observed in other tumor models and appears to be a response that is dependent on oligoHA and CD44 interaction. Oligo-HA, competitively blocked binding of endogenous HMW-HA to CD44, consequently attenuating downstream signaling to the PI3K/Akt cell survival pathway, leading to inhibited tumor growth and apoptosis $(143,144)$. Furthermore, oligo-HA suppressed glioma growth in vivo, in part through inhibiting recruitment of progenitor $\mathrm{BRCP}+$ stem cells (145). There is also evidence that oligo-HA abrogated cell-associated matrices and HA retention via CD44 in osteosarcoma, resulting in apoptosis and importantly, suppression of the formation of lung metastases (31).

\section{MMW-HA and LMW-HA - Caught in the Middle?}

Low molecular weight-HA and MMW-HA fragments are frequently detected as polydisperse fractions with overlapping MW distributions. They could be considered intermediate fractions, and arise due to partial fragmentation due to varying concentrations of Hyal, ROS/RNS, as well as the availability of cleavage sites depending on HA interactions with its receptors and other ECM proteins. There is also the possibility that these fractions contain nascent HA that has not yet reached its full length. Taking this into account, MMW-HA and LMW-HA have roles that overlap with either HMW-HA or oligo-HA.

Low molecular weight-MMW-HA has been reported to facilitate the differentiation of many mesenchymal cells that are activated as a normal response following injury, including chondrocytes (146), fibroblasts [together with their expression of growth factors FGF-2 and KGF (147)], keratinocytes (148), and VSMCs. VSMC differentiation was associated with increased collagen deposition (149). LMW-HA improved dermal excisional would repair, associated with increased expression of CD44 and RHAMM and deposition of type-III collagen in aged mice (150). A separate study also showed improved age-related skin function, when HA was administered to patients with skin atrophy in a CD44-dependent manner (151). Topical administration of LMW-HA also acts as a scavenging agent following xenobiotic treatment (and ROS generation), promoting wound healing in excisional and incisional wound models (152). In the lung, LMW-HA protected against porcine pancreatic elastase-induced bronchoconstriction (153). Its protective effect against elastase was confirmed in a second model where aerosolized LMWHA blocked experimental emphysema induced by intra-tracheal administration of elastase (154). Conversely, administration of LMW-HA exacerbated ozone-induced airway hyper-reactivity in a CD44-dependent manner, also in the lung, whereas treatment with HMW-HA protected against ozone injury (155). LMWHA, via TLR4-mediated receptor binding, induced neutrophil apoptosis via an IFN $\beta$, TRAIL/TRAILR-dependent mechanism, thus protecting against prolonged inflammation following injury (156). LMW-HA has also been reported to induce apoptosis of myeloid cells via CD44-dependent, tyrosine kinase signaling (157). Its protective effects have additionally been reported in the liver and intestine, by preventing hepatocellular apoptosis via NF- $\kappa \mathrm{B}$ (158) and the expression of murine $\beta$-defensin 3 (an ortholog of human $\beta$-defensin 2) via TLR4, respectively (159).

Low molecular weight-HA and MMW-HA promote inflammation through direct and indirect signaling mechanisms. Directly, polydisperse LMW-MMW-HA increases inflammatory gene expression and decreases anti-inflammatory signaling in macrophages by downregulating surface expression of $\mathrm{A} 2 \mathrm{aR}$, via CD44 and PKC (160). LMW-MMW-HA binding to HARE has also been shown to activate pro-inflammatory NF- $\kappa \mathrm{B}$ signaling (161). Conversely, LMW-MMW-HA activates the innate immune response via TLR2 and MyD88 (162). LMW-HA can mobilize leukocytes but not hematopoietic progenitor cells to the circulation (163) and increase NO production in primary macrophages (164). Importantly, the activation of elicited, versus resident peritoneal macrophages by LMW-HA have distinct requirements. Both cell types produce pro-inflammatory cytokines (including IL-12) in response to LMW-HA via LMWHA-CD44 signaling; however, resident macrophages require adhesion-dependent priming to respond to LMW-HA (165). Other pro-inflammatory cytokines released following LMW-HA stimulation include MIP1- $\alpha$, MCP-1, RANTES, and Crg-2 (166). LMW-MMW-HA is also a potent stimulator of eicosanoids 
(including induction of COX2 and PGE2 production via ERK1/2 p38 and JNK signaling) in primary human monocytes and murine wild-type bone marrow-derived monocytes. This activation was also dependent on a HA-TLR4/MyD88 pathway (167). LMWHA can also influence macrophage polarity. M0 (undifferentiated) and M2 (pro-fibrotic) macrophages can be switched to an M1 (pro-inflammatory) phenotype after a short period of stimulation with LMW-HA (167). However, prolonged exposure to LMW-HA can induce the M2 phenotype (168).

Indirectly, LMW-MMW-HA can stimulate the production of pro-inflammatory stimuli from other cell types. Lung epithelial cells, chondrocytes, liver ECs, and VSMCs release a number of pro-inflammatory cytokines in response to LMW-HA via its binding to CD44 or TLR4, including TNF $\alpha$, IL-1 $\beta$, MMP-13, and iNOS (169-174). In VSMCs, LMW-HA also stimulated cell proliferation and migration via CD44 through ERK1/2 and RhoA signaling $(173,175)$. One study also found that TLR4 interacts with CD44 in response to LMW-HA and together act as a brake in LMW-HA-induced lung inflammation (176). In vivo, LMWHA promoted splenocyte proliferation, macrophage activation, while suppressing angiogenesis in chicken embryos (177). LMW$\mathrm{HA}$ is critical in the induced fetal growth response to uterine ischemia/reperfusion via TLR4 (178). LMW-HA also decreases the rate of early wound contraction in skin (107), but increased total number of recruited macrophages in the granulation tissue (132).

\section{LMW-MMW-HA and Cancer Progression}

In the tumor microenvironment (TME), LMW-MMW-HA has the potential to influence cancer cells, stromal cells, ECs, and infiltrating inflammatory cells. Specifically, LMW-HA facilitates tumor cell adhesion and migration. In fibrosarcoma, this was shown to be dependent on LMW-HA-RHAMM binding, which influenced downstream FAK and ERK1/2 signaling (179). LMWHA enhanced proliferation (though MAPK and c-fos signaling) and adhesion of LM8 murine osteosarcoma cells with increased MMP-2 secretion. Adhesion in these cells was shown to be dependent on CD44 (180). In fact, LMW-HA-CD44-dependent signaling has been reported in a number of carcinoma cells to activate NF- $\kappa \mathrm{B}$ signaling via a Ras-PKC $\zeta-\mathrm{I} \kappa \mathrm{B}$ cascade (181), and thus may be one of the many ways in which LMW-HA promotes tumor progression by the activation of cell proliferation. However, much like what has been found for oligo-HA in the TME, LMW-MMW-HA can also inhibit growth of some tumors. MMW-HA stimulated iNOS and subsequent NO production and apoptosis in DCs in vivo in glioma. This process was dependent on HA-CD44 interaction and suggests that HA in gliomas may contribute to immunosuppression by promoting apoptosis of infiltrating immune cells (182). In contrasting findings to those above, LMW-HA inhibited colorectal carcinoma growth in vivo, by inhibiting tumor cell proliferation via Akt signaling (183). The TME was also affected; LMW-HA induced immunity against the carcinoma by stimulating DC migration, proliferation, and the release of IL-12 and IFN $\gamma$, while simultaneously decreasing their release of immunosuppressive IL-10. Interestingly, these responses occurred in a CD44 and TLR4-independent manner (184).

\section{CD44 - An Important Regulator of HA-Mediated Signaling in Cancer?}

Among the receptors involved in HA signaling, CD44 is the most abundant, expressed in almost all tissues and across nearly every cell type. Additionally, this type I transmembrane protein is able to bind almost all HA MW species, with the exception of oligo-HA fragments smaller than six saccharides in length (16). Combined, these two contributing factors can arguably account for the variety of different functions of HA-CD44 interactions in vivo, any of which could have important outcomes on tumorigenesis.

As well as being bound to the plasma membrane, CD44 can exist as a cleaved, matrix-associated fragment and as a soluble protein and can independently affect cellular function (185, 186). CD44 also exists as a number of splice variants, which are commonly expressed in tumor cells (6). These variants encode additional segments in the membrane proximal region of the extracellular domain that can be differentially glycosylated (187, 188). The CD44 cytoplasmic domain is known to be required for HA binding, the formation and retention of pericellular matrix, and CD44-mediated endocytosis of HA $(189,190)$. Furthermore, cell adhesion via HA binding can be regulated in part by variable glycosylation of its CD44 extracellular domain, as increased glycosylation inhibits HA recognition (191). These post-translational modifications ( $\mathrm{N}$ and $\mathrm{O}$ glycosylation) of CD44 also affect its ability to signal and shed from the cell surface; however, CD44 cleavage can also occur via a glycosylation-independent mechanism via MMP cleavage (192). Interestingly, murine M0 macrophages when stimulated to induce pro-inflammatory M1 polarization (with LPS/IFN $\gamma$ ), upregulate their CD44 expression and ability to bind HA. Conversely, M0 macrophages polarized to the antiinflammatory M2 phenotype (with IL-4) also upregulate CD44 expression but with no increase in HA binding. This difference was a consequence of the loss of chondroitin sulfation on CD44 in M1s and conversely an upregulation of chondroitin sulfation on CD44 in M2s (193). It is as-yet unclear if this dynamic physiological regulation of hyaluronan binding also influences the phenotypic differences between the two cell types and the inflammatory state of the TME. Nevertheless, the ability to alter macrophage polarization via CD44 offers a potentially new mechanism to target the inflammatory response in vivo, in the context of tumor progression as well as other inflammatory conditions, such as wound healing, lung injury, and atherosclerosis.

CD44 knockout mice are viable and fertile with a modest phenotype; progenitor cell egress from the bone marrow is slightly impaired (194). However, under pathological conditions, deletion of CD44 has profound effects on tissue architecture, signaling, and disease outcome. In a model of non-infectious lung injury, CD44null mice succumb to unremitting inflammation with impaired clearance of neutrophils, persistent accumulation of LMW-HA, and impaired activation of TGF- $\beta$. This phenotype was partially restored by reconstitution with $\mathrm{CD} 44^{+}$bone marrow-derived cells (195). In contrast, we previously reported that CD44 promotes auto-inflammatory disease progression in a mouse model of atherosclerosis. CD44 expression correlated with increased lesional macrophage and HA content and VSMC activation (196). Furthermore, CD44 on both bone marrow-derived and nonbone marrow-derived cells was important; CD44 on leukocytes 
in part promoted the disease via enhancing macrophage and Tcell recruitment to lesions in vivo. Leukocyte to EC adhesion and transmigration was also CD44-dependent as was macrophage activation. CD44 on VSMCs also promoted their migration and proliferation (197). Interestingly, we also reported that CD44 is selectively upregulated in athero-prone regions, and CD44 signaling impacts gene expression profiles in the vasculature, including those genes involved with focal adhesion formation, ECM deposition, inflammation, and angiogenesis (198).

CD44 is known to facilitate the rolling and adhesion of circulating leukocytes on the endothelium, and subsequent transendothelial migration (14, 199-201). Targeted inhibition of HA-CD44 binding using a synthetic peptide inhibits leukocyte adhesion and trafficking in vivo (202). HMW-HA-CD44 binding in calveolinenriched microdomains (CEMs) in ECs also promotes barrier function, via the recruitment of c-met, Tiam1, Rac1, dynamin 2, and cortactin to CEMs and their redistribution to areas of cell-cell contact $(203,204)$. Any alterations to HA-CD44 interaction could, therefore, potentially alter the recruitment of immune cells or the intravasation of tumor cells to the blood stream or extravasation to tissue during metastasis. Administration of LMW-HA suppresses A2aR (a negative regulator of inflammation) via CD44 binding and downstream PKC signaling following lung injury in vivo (160). The HA receptor TLR4 has been shown to interact directly with CD44 in order to limit LMWHA-induced lung inflammation in vivo (176). Antisense CD44 inhibited HA binding, tumor growth, and metastasis of colorectal carcinoma cells to the liver (205). Furthermore, peptide inhibition of CD44-HA binding significantly reduced seeding and tumor growth of intravenously introduced B16-F10 melanoma cells in lungs in a model of metastasis (206). Indeed, HA-CD44 interaction has been implicated in the growth of a number of cancers (6). The growth-inhibitory and tumor-suppressive effects of p53 act in part via its ability to bind to a non-canonical sequence in the CD44 promoter, thus inhibiting CD44 expression and downstream tumor-promoting signaling in breast cancer cells (207). Furthermore, a separate study found that human miRNAs miR373, and miR-520c suppressed CD44 expression, leading to the promotion of breast tumor cell migration and invasion in vitro and in vivo (208). The standard form of CD44 (CD44s) and CD44v6 are involved in breast cancer cell adhesion and motility via interactions with HA (209). This increased cell motility perhaps occurs as a result of modulation of CD44 into clusters by HMW-HA on the plasma membrane (210). CD44 clusters facilitate cell binding and internalization of HA thus enabling invasion from tumor masses into the surrounding ECM (211). Observation of neuroblastoma cells revealed that these CD44 clusters localized to filopodia and focal bleb-like protrusions in neuroblastoma cells that enabled migration and invasive growth into brain tissue (212). In another study, chondroitin sulfate E fragments enhanced CD44 cleavage and tumor cell motility upon degradation. Much like LMW-HA, these degradation products modulated tumor cell adhesion and migration by binding to CD44 (213). In a separate finding, the non-coding $3^{\prime} \mathrm{UTR}$ of CD44 was found to act as a binding site for miRNAs that targeted the genes for Col1 $\alpha 1$ and fibronectin. Overexpression of the CD44 3'UTR in MDA-MB231 cells antagonized the effects of the
miRNAs on their specific targets and upregulated collagen and fibronectin expression that in turn enhanced tumor cell migration and metastasis in vivo (214).

Stromal expression of ECM proteins and GAGs is increased in activated fibroblasts in the TME and is thought to promote tumor cell migration. Thus, targeting CD44 signaling in stromal cells in the TME may also provide a separate avenue to target tumorigenesis. Indeed, CD44 has been implicated in stromal cell function in a number of pathological settings. CD44 facilitates the healing response, by promoting fibroblast infiltration, proliferation, myofibroblast differentiation, and ECM deposition and remodeling following myocardial infarction $(215,216)$. Fibroblast migration is mediated by CD44-dependent TGF- $\beta$ activation that promotes stress-fiber formation and directional migration (217). The HA receptor RHAMM may also facilitate cell migration via the regulation of CD44-Erk1/2 complexes at the cell surface (218). Cell proliferation via CD44 is dependent upon the MW of the HA ligand. In VSMCs, HMW-HA binding to CD44 selectively inhibits the GTP loading of Rac and Rac-dependent signaling to cyclin D1 (thereby inhibiting proliferation), whereas LMW-HA binding to CD44 selectively stimulates ERK activation and ERK-dependent cyclin D1 expression [thus promoting proliferation (175)]. Interestingly, HA binding to CD44 increases as a function of HA size. Half maximal saturation is reached with a HA MW of only $30 \mathrm{kDa}$. Reversible binding was confined to oligo-HA fragments $(<10 \mathrm{kDa})$, with interactions essentially irreversible with large polymers $[>30 \mathrm{kDa}$ (219)]. The accumulation of oligo-HA in tumors, combined with increased CD44 expression, may, therefore, be a mechanism to activate alternate, pro-tumorigenic signaling pathways as a means to bypass and eventually overcome the nonreversible protective signals stemming from HMW-HA-CD44 binding.

\section{Conclusions, Caveats, and Perspectives}

In revisiting the literature, we found that little was known about how HA MW distribution changes in vivo during disease, especially when compared with the number of studies that reported changes in HA content in pathological settings. Much of what is known about HA MW in disease in vivo has been extrapolated from in vitro cell culture experiments and only a handful of early articles where it was analyzed in vivo. Furthermore, the limited number of studies, which we found that reported the occurrence of oligo-HA in tissue (five in total) question the pathophysiologic relevance of oligo-HA, and its effects on cell function in vivo. Many studies have tested the biological activity of HA (from oligo-HA to HMW-HA) as an exogenously added ligand to cells in culture (with some extending these experiments in vivo), and its effects on cellular signaling, gene/protein expression, and cell behavior; some revisited how it changed endogenous HA, including its localization, matrix organization, and cross-linking and turnover, but very few specifically analyzed its effects on endogenous MW distribution. One could argue that HA MW analysis is not a straightforward technology. There are no commercial kits that allow HA MW profiles to be analyzed in a high throughput fashion. Additionally, care has to be taken to first extract HA from its 
link proteins, HCs, and other ECM molecules with which it forms higher ordered structures, while simultaneously taking measures to prevent loss of the smaller oligo-HA fragments during purification. The commercially available kits for measuring HA concentration (ELISA and ELISA-like assays) also vary, with some unable to detect HA polymers accurately at the extremes of the MW spectrum (220). On the other hand, thanks to a number of dedicated groups, a variety of reliable methodologies for HA MW analysis do exist, using combinations of size-exclusion chromatography (221), flat-bed polyacrylamide electrophoresis $(222,223)$, agarose gel electrophoresis (223-227), gas phase electrophoretic mobility molecular analysis [GEMMA (228)], or asymmetrical flow field fractionation with multi-angle light scattering $(229,230)$, for continuous HA size profiling. Consequently, we anticipate the increased use of these robust methodologies to monitor HA size in various pathological settings in vivo in future studies.

High molecular weight HA and oligo-HA exist as distinct pools of HA with unique biological properties at the opposite ends of the HA MW spectrum. On the other hand, LMW-HA and MMW$\mathrm{HA}$ are frequently detected as polydisperse fractions that often overlap. When searching for articles related to LMW-HA and MMW-HA in the literature, we found that the MW range was not always reported, instead being replaced with the average MW for the sample. This was found to be very common in earlier studies, and where LMW-HA or MMW-HA fractions were added exogenously as extracellular cues to examine their effects on cell function. These LMW and MMW fractions were purchased from various companies, with the HA sourced from various tissues from different species. Those most commonly used included umbilical cord (human), rooster comb, trachea and vitreous humor (bovine), and a synthetic polymer of HMW-HA produced by Pharmacia (known as Healon). The polydisperse MW ranges of
HA for these preparations are given in Figure 1. Umbilical cord HA was found to be commonly used in the literature as LMW-HA. We compared umbilical cord HA fractions from three separate vendors. Remarkably, the MW distribution of umbilical cord HA was hugely polydisperse and varied depending on the vendor, ranging from $30-1000 \mathrm{kDa}$ for HA from ICN (MP Biomedicals) to $900-3500 \mathrm{kDa}$ from Sigma, and $200-3000 \mathrm{kDa}$ when obtained from Calbiochem. Two of the sources of umbilical cord HA (Sigma and Calbiochem) contained a significant proportion of HMW $(>1000 \mathrm{kDa}) \mathrm{HA}$. This high degree of variation in HA MW may account for some of the opposing data we found regarding the function of LMW-HA in the literature where umbilical cord HA had been used. We were only able to obtain single vendor samples for tracheal, vitreous humor, and rooster comb HA. The MW distribution of HA in these fractions in comparison were much narrower, with tracheal and vitreous humor $\mathrm{HA}$ in the $30-300 \mathrm{kDa}$ range (LMW) and rooster comb at 600-3000 kDa (MMW-HMW). The synthetic, Healon HA could be considered very high, at $3500-4500 \mathrm{kDa})$. In order to better understand and compare the roles of HMW-HA versus HA fragments in future studies, nonoverlapping HA MW samples with reduced polydispersity for each sized group will help define the often contrasting roles of $\mathrm{HA}$ on cell function. To this end, it appears that using umbilical cord HA may not be best suited for this purpose. In any case, HA from this source does not appear to be any longer available, nor is HA from bovine trachea. This leaves Healon, rooster comb HA, and vitreous humor HA as three sources, with non-overlapping MW profiles that can be confidently used to investigate the unique individual roles of different HA MWs on tissue function and disease outcome in future studies. This would be along with the use of LMW-HA, oligo-HA, and narrow-range HA preparations manufactured using unique bacterial fermentation technologies

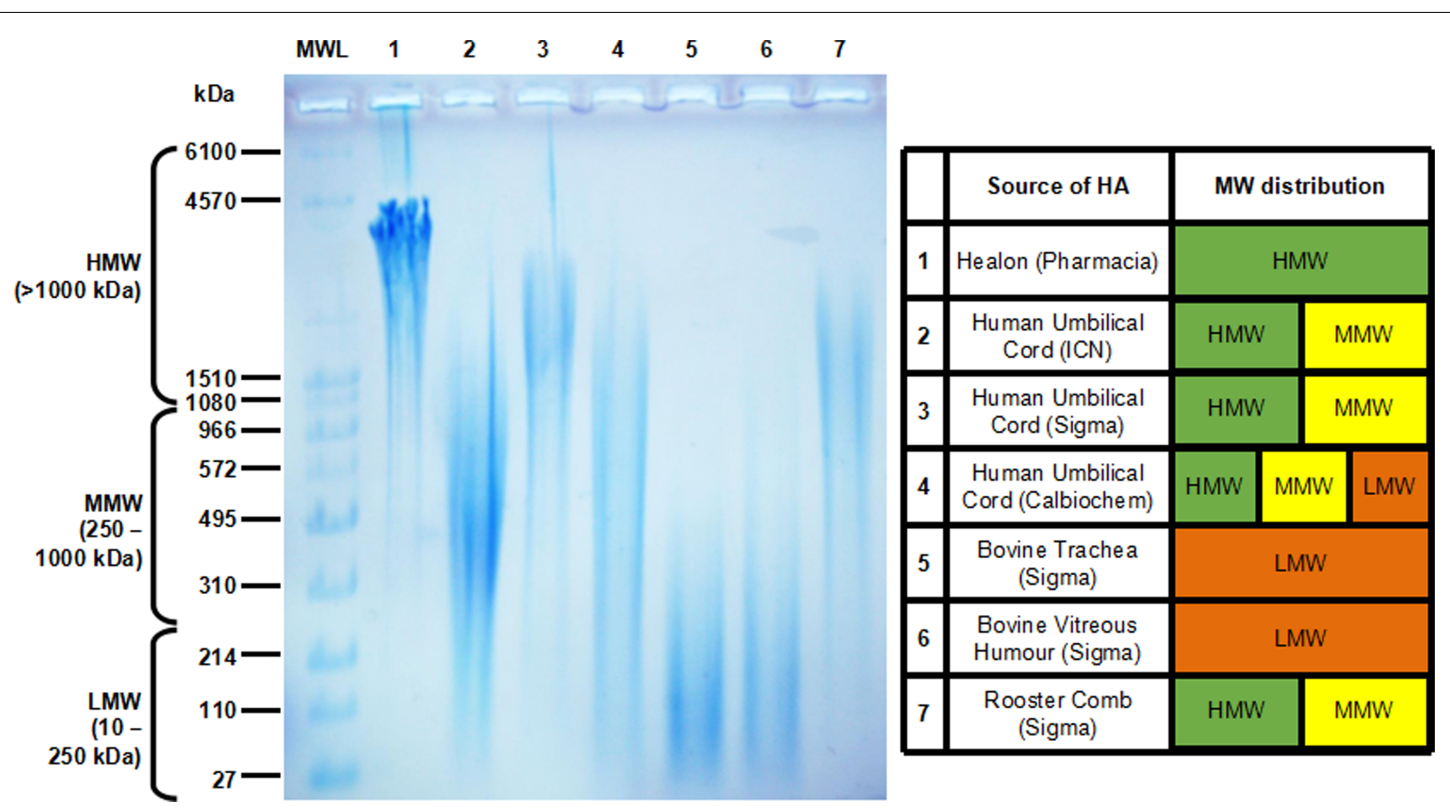

FIGURE 1 | Agarose gel electrophoresis showing the molecular weight (MW) distribution of commercially available HA (left) and charted for comparison (right). Molecular weight HA ladder (MWL) was purchased from Hyalose (combined mega, high, and low ladders). HA MW is divided into high (HMW >1000 kDa), medium (MMW, 250-1000 kDa), and low (10-250 kDa). 


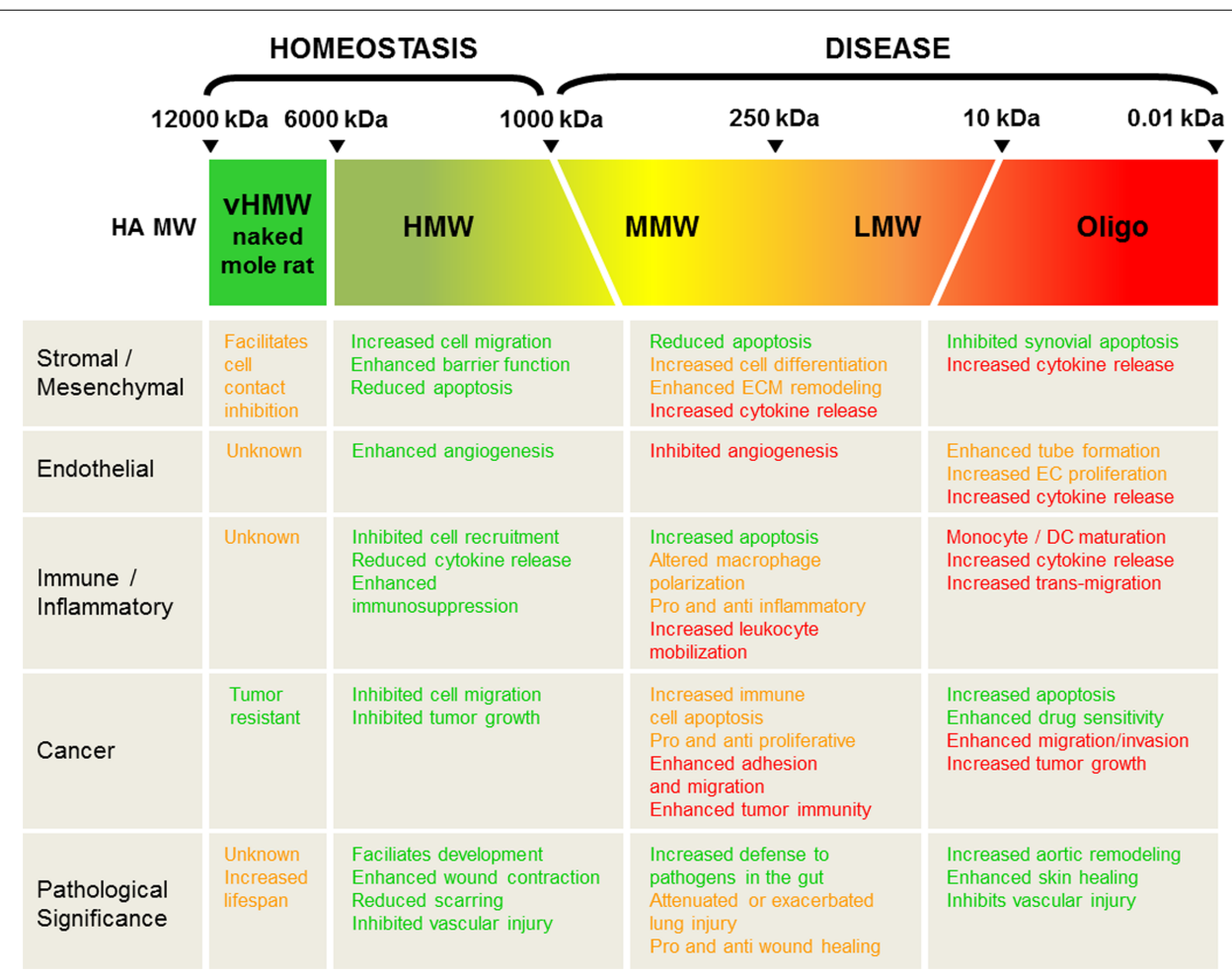

FIGURE 2 | Summary and pathological significance of HA size

in vivo. $\mathrm{HA}$ molecular weight $(\mathrm{MW})$ is divided into very high (VHMW 6000-12000 kDa; naked mole rat HA), high (HMW > 1000 kDa), medium (MMW 250-1000 kDa), low (10-250 kDa), and Oligo-HA
$(<10 \mathrm{kDa})$. Green text highlights positive roles for each HA MW in tissue function and recovery, whereas red text favors pathological decline. Opposing and/or unclear tissue responses are designated in orange-colored text. (spearheaded by Hyalose and now offered by other vendors) that are now readily available (231-233).

Depending on the pathological setting, HA fragmentation may be good or bad, pro- or anti-inflammatory, aid in tissue recovery or promote disease progression, as summarized in Figure 2. The complexity in part arises due to the number of different signaling mechanisms that result from HA itself acting as a ligand; it can mediate alternate and often opposing effects via different, yet often the same receptors. Furthermore, HA in tissue is often found as a polydisperse molecule, often covering a MW range from 20 to $2000 \mathrm{kDa}$ with no one, specific length of HA polymer dominating during disease. It is, therefore, interesting that in its polydisperse state, HA can produce such contrasting signaling cues compared to what is exerted by native, HMW-HA in homeostasis. It is possible that changes in HA-mediated cellular signaling occur when a small percent of this polydisperse-fragmented pool passes a threshold that is enough to tip the balance and change the outcome of cellular function. Indeed, we have previously proposed that CD44 may act as a rheostat for cell proliferation through its ability to activate alternative signaling pathways via the binding of HMW-HA versus LMW-HA (22). As small pools of HA fragments have the propensity to do this, it is, therefore, conceivable that therapies to induce even possibly quite modest changes in the ratio of the active HA fragments would be enough to shift the balance of signaling in the favor of tissue repair and recovery. For example, small adjustments in increasing the ratio of HMWHA to HA fragments may be enough to keep disease in check.
On the other hand, there may be occasions where decreasing this ratio, and increasing the levels of specific HA fragments may also be beneficial. Importantly, the total concentration of HA fragments versus native, HMW-HA also needs to be measured and addressed; simply flooding the system with any size HA might be expected to cause detrimental effects to the tissue. Understanding, therefore, how HA MW distribution changes in vivo in different pathological settings, together with the shifts and trends that alter HA signaling, will be crucially important in deciding when and where to intervene to alter the course of disease progression.

It is clear that there is a substantial body of work that has investigated the biological and signaling roles of HMW-HA, MMW-HA, LMW-HA, and oligo-HA on cell function and disease outcome. Collectively, the data suggest that using HMW-HA may be a suitable course of action to aid tissue recovery and a return to homeostasis (Figure 2). This has certainly been the case for the treatment of arthritis (234). Other important avenues of research have pinpointed a pivotal role for $\mathrm{HA}$ in the regenerative properties of fetal tissues, which unlike their adult counterparts, heal without scarring (235), although the mechanisms by which this occurs remains to be elucidated. A less well-studied area is how MMW-HA, LMW-HA, and oligo-HA impact the biophysical and rheological properties of the tissue microenvironment or the biomechanical properties of HA in the pericellular and ECM. Going forward, these also offer important and exciting areas of investigation that may offer new therapeutic perspectives 
on targeting HA biology in tumor and disease progression and restoration of homeostasis.

\section{Acknowledgments}

The authors acknowledge financial support from grants 5PO1HL-66250 and R01-HL093283 from the National Institute of Health.

\section{References}

1. Meyer K, Palmer JW. The polysaccharide of the vitreous humor. J Biol Chem (1934) 107:629-34.

2. Simpson MA, Heldin P, editors. Hyaluronan signaling and turnover. $A d v$ Cancer Res (2014) 123:1-385.

3. Fraser JR, Laurent TC, Laurent UB. Hyaluronan: its nature, distribution, functions and turnover. J Intern Med (1997) 242:27-33. doi:10.1046/j.1365-2796. 1997.00170.x

4. Jiang D, Liang J, Noble PW. Hyaluronan as an immune regulator in human diseases. Physiol Rev (2011) 91:221-64. doi:10.1152/physrev.00052.2009

5. Toole BP, Wight TN, Tammi MI. Hyaluronan-cell interactions in cancer and vascular disease. J Biol Chem (2002) 277:4593-6. doi:10.1074/jbc.R100039200

6. Misra S, Heldin P, Hascall VC, Karamanos NK, Skandalis SS, Markwald RR, et al. Hyaluronan-CD44 interactions as potential targets for cancer therapy. FEBS J (2011) 278:1429-43. doi:10.1111/j.1742-4658.2011.08071.x

7. Toole BP. Hyaluronan promotes the malignant phenotype. Glycobiology (2002) 12:37R-42R. doi:10.1093/glycob/12.3.37R

8. Aya KL, Stern R. Hyaluronan in wound healing: rediscovering a major player. Wound Repair Regen (2014) 22:579-93. doi:10.1111/wrr.12214

9. Singleton PA, Lennon FE. Acute lung injury regulation by hyaluronan. J Allergy Ther (2011) (Suppl 4):S4-003. doi:10.4172/2155-6121.S4-003

10. Ruppert SM, Hawn TR, Arrigoni A, Wight TN, Bollyky PL. Tissue integrity signals communicated by high-molecular weight hyaluronan and the resolution of inflammation. Immunol Res (2014) 58:186-92. doi:10.1007/ s12026-014-8495-2

11. Wang A, de la Motte C, Lauer M, Hascall V. Hyaluronan matrices in pathobiological processes. FEBS J (2011) 278:1412-8. doi:10.1111/j.1742-4658.2011. 08069.x

12. Petrey AC, de la Motte CA. Hyaluronan, a crucial regulator of inflammation. Front Immunol (2014) 5:101. doi:10.3389/fimmu.2014.00101

13. Jiang D, Liang J, Noble PW. Hyaluronan in tissue injury and repair. Annu Rev Cell Dev Biol (2007) 23:435-61. doi:10.1146/annurev.cellbio.23.090506. 123337

14. Puré E, Cuff CA. A crucial role for CD44 in inflammation. Trends Mol Med (2001) 7:213-21. doi:10.1016/S1471-4914(01)01963-3

15. Orian-Rousseau V, Sleeman J. CD44 is a multidomain signaling platform that integrates extracellular matrix cues with growth factor and cytokine signals. Adv Cancer Res (2014) 123:231-54. doi:10.1016/B978-0-12-800092-2. 00009-5

16. Stern R, Asari AA, Sugahara KN. Hyaluronan fragments: an information-rich system. Eur J Cell Biol (2006) 85:699-715. doi:10.1016/j.ejcb.2006.05.009

17. Singleton PA. Hyaluronan regulation of endothelial barrier function in cancer. Adv Cancer Res (2014) 123:191-209. doi:10.1016/B978-0-12-800092-2. 00007-1

18. Pardue EL, Ibrahim S, Ramamurthi A. Role of hyaluronan in angiogenesis and its utility to angiogenic tissue engineering. Organogenesis (2008) 4:203-14. doi:10.4161/org.4.4.6926

19. Ghosh P, Guidolin D. Potential mechanism of action of intra-articular hyaluronan therapy in osteoarthritis: are the effects molecular weight dependent? Semin Arthritis Rheum (2002) 32:10-37. doi:10.1053/sarh.2002.33720

20. Toole BP. Hyaluronan-CD44 interactions in cancer: paradoxes and possibilities. Clin Cancer Res (2009) 15:7462-8. doi:10.1158/1078-0432.CCR-09-0479

21. Tian X, Azpurua J, Hine C, Vaidya A, Myakishev-Rempel M, Ablaeva J, et al. High-molecular-mass hyaluronan mediates the cancer resistance of the naked mole rat. Nature (2013) 499:346-9. doi:10.1038/nature12234

22. Puré E, Assoian RK. Rheostatic signaling by CD44 and hyaluronan. Cell Signal (2009) 21:651-5. doi:10.1016/j.cellsig.2009.01.024

\section{Supplementary Material}

The Supplementary Material for this article can be found online at http://journal.frontiersin.org/article/10.3389/fimmu.2015.00231

Table S1 | HA size in tissue in vivo. HA molecular weight (MW) is divided into High (HMW >1000 kDa), Medium (MMW 250-1000 kDa), Low (10-250 kDa), and Oligo-HA $(<10 \mathrm{kDa})$.

23. Kultti A, Li X, Jiang P, Thompson CB, Frost GI, Shepard HM. Therapeutic targeting of hyaluronan in the tumor stroma. Cancers (Basel) (2012) 4:873-903. doi: $10.3390 /$ cancers 4030873

24. Karousou E, D’Angelo ML, Kouvidi K, Vigetti D, Viola M, Nikitovic D, et al. Collagen VI and hyaluronan: the common role in breast cancer. Biomed Res Int (2014) 2014:606458. doi:10.1155/2014/606458

25. West DC, Hampson IN, Arnold F, Kumar S. Angiogenesis induced by degradation products of hyaluronic acid. Science (1985) 228:1324-6. doi:10.1126/ science. 2408340

26. Hawkins CL, Davies MJ. Degradation of hyaluronic acid, poly- and monosaccharides, and model compounds by hypochlorite: evidence for radical intermediates and fragmentation. Free Radic Biol Med (1998) 24:1396-410. doi:10. 1016/S0891-5849(98)00009-4

27. Rosines E, Schmidt HJ, Nigam SK. The effect of hyaluronic acid size and concentration on branching morphogenesis and tubule differentiation in developing kidney culture systems: potential applications to engineering of renal tissues. Biomaterials (2007) 28:4806-17. doi:10.1016/j.biomaterials.2007.07.034

28. Dang S, Peng Y, Ye L, Wang Y, Qian Z, Chen Y, et al. Stimulation of TLR4 by LMW-HA induces metastasis in human papillary thyroid carcinoma through CXCR7. Clin Dev Immunol (2013) 2013:712561. doi:10.1155/2013/712561

29. Suzuki M, Kobayashi H, Kanayama N, Nishida T, Takigawa M, Terao T. CD44 stimulation by fragmented hyaluronic acid induces upregulation and tyrosine phosphorylation of c-Met receptor protein in human chondrosarcoma cells. Biochim Biophys Acta (2002) 1591:37-44. doi:10.1016/S0167-4889(02) 00246-X

30. Sugahara KN, Hirata T, Hayasaka H, Stern R, Murai T, Miyasaka M. Tumor cells enhance their own CD44 cleavage and motility by generating hyaluronan fragments. J Biol Chem (2006) 281:5861-8. doi:10.1074/jbc.M506740200

31. Hosono K, Nishida Y, Knudson W, Knudson CB, Naruse T, Suzuki Y, et al. Hyaluronan oligosaccharides inhibit tumorigenicity of osteosarcoma cell lines MG-63 and LM-8 in vitro and in vivo via perturbation of hyaluronan-rich pericellular matrix of the cells. Am J Pathol (2007) 171:274-86. doi:10.2353/ ajpath.2007.060828

32. Khaldoyanidi SK, Goncharova V, Mueller B, Schraufstatter IU. Hyaluronan in the healthy and malignant hematopoietic microenvironment. Adv Cancer Res (2014) 123:149-89. doi:10.1016/B978-0-12-800092-2.00006-X

33. Itano $\mathrm{N}$, Sawai $\mathrm{T}$, Yoshida M, Lenas P, Yamada $\mathrm{Y}$, Imagawa M, et al. Three isoforms of mammalian hyaluronan synthases have distinct enzymatic properties. J Biol Chem (1999) 274:25085-92. doi:10.1074/jbc.274.35.25085

34. Mohamadzadeh M, DeGrendele H, Arizpe H, Estess P, Siegelman M. Proinflammatory stimuli regulate endothelial hyaluronan expression and CD44/HA-dependent primary adhesion. J Clin Invest (1998) 101:97-108. doi:10.1172/JCI1604

35. Wilkinson TS, Potter-Perigo S, Tsoi C, Altman LC, Wight TN. Pro- and anti-inflammatory factors cooperate to control hyaluronan synthesis in lung fibroblasts. Am J Respir Cell Mol Biol (2004) 31:92-9. doi:10.1165/rcmb. 2003-0380OC

36. Vigetti D, Genasetti A, Karousou E, Viola M, Moretto P, Clerici M, et al. Proinflammatory cytokines induce hyaluronan synthesis and monocyte adhesion in human endothelial cells through hyaluronan synthase 2 (HAS2) and the nuclear factor-kappaB (NF-kappaB) pathway. J Biol Chem (2010) 285:24639-45. doi:10.1074/jbc.M110.134536

37. Estess P, Nandi A, Mohamadzadeh M, Siegelman MH. Interleukin 15 induces endothelial hyaluronan expression in vitro and promotes activated $\mathrm{T}$ cell extravasation through a CD44-dependent pathway in vivo. J Exp Med (1999) 190:9-19. doi:10.1084/jem.190.1.9

38. Stuhlmeier KM, Pollaschek C. Differential effect of transforming growth factor beta (TGF-beta) on the genes encoding hyaluronan synthases and utilization 
of the p38 MAPK pathway in TGF-beta-induced hyaluronan synthase 1 activation. J Biol Chem (2004) 279:8753-60. doi:10.1074/jbc.M303945200

39. Jacobson A, Brinck J, Briskin MJ, Spicer AP, Heldin P. Expression of human hyaluronan synthases in response to external stimuli. Biochem J (2000) $348(\mathrm{Pt}$ 1):29-35. doi:10.1042/0264-6021:3480029

40. Heldin P, Asplund T, Ytterberg D, Thelin S, Laurent TC. Characterization of the molecular mechanism involved in the activation of hyaluronan synthetase by platelet-derived growth factor in human mesothelial cells. Biochem J (1992) 283(Pt 1):165-70.

41. Monslow J, Sato N, Mack JA, Maytin EV. Wounding-induced synthesis of hyaluronic acid in organotypic epidermal cultures requires the release of heparin-binding egf and activation of the EGFR. J Invest Dermatol (2009) 129:2046-58. doi:10.1038/jid.2009.9

42. Pienimaki JP, Rilla K, Fulop C, Sironen RK, Karvinen S, Pasonen S, et al. Epidermal growth factor activates hyaluronan synthase 2 in epidermal keratinocytes and increases pericellular and intracellular hyaluronan. J Biol Chem (2001) 276:20428-35. doi:10.1074/jbc.M007601200

43. Yamane T, Kobayashi-Hattori K, Oishi Y. Adiponectin promotes hyaluronan synthesis along with increases in hyaluronan synthase 2 transcripts through an AMP-activated protein kinase/peroxisome proliferator-activated receptor$\alpha$-dependent pathway in human dermal fibroblasts. Biochem Biophys Res Commun (2011) 415:235-8. doi:10.1016/j.bbrc.2011.09.151

44. Bourguignon LYW, Gilad E, Peyrollier K. Heregulin-mediated ErbB2-ERK signaling activates hyaluronan synthases leading to $\mathrm{CD} 44$-dependent ovarian tumor cell growth and migration. J Biol Chem (2007) 282:19426-41. doi:10. 1074/jbc.M610054200

45. Vigetti D, Deleonibus S, Moretto P, Karousou E, Viola M, Bartolini B, et al. Role of UDP-N-acetylglucosamine (GlcNAc) and O-GlcNAcylation of hyaluronan synthase 2 in the control of chondroitin sulfate and hyaluronan synthesis. $J$ Biol Chem (2012) 287:35544-55. doi:10.1074/jbc.M112.402347

46. Karousou E, Kamiryo M, Skandalis SS, Ruusala A, Asteriou T, Passi A, et al. The activity of hyaluronan synthase 2 is regulated by dimerization and ubiquitination. J Biol Chem (2010) 285:23647-54. doi:10.1074/jbc.M110.127050

47. Vigetti D, Karousou E, Viola M, Deleonibus S, De Luca G, Passi A. Hyaluronan: biosynthesis and signaling. Biochim Biophys Acta (2014) 1840:2452-9. doi:10. 1016/j.bbagen.2014.02.001

48. Michael DR, Phillips AO, Krupa A, Martin J, Redman JE, Altaher A, et al. The human hyaluronan synthase 2 (HAS2) gene and its natural antisense RNA exhibit coordinated expression in the renal proximal tubular epithelial cell. $J$ Biol Chem (2011) 286:19523-32. doi:10.1074/jbc.M111.233916

49. Stern R, Jedrzejas MJ. Hyaluronidases: their genomics, structures, and mechanisms of action. Chem Rev (2006) 106:818-39. doi:10.1021/cr050247k

50. Mochizuki S, Kano A, Shimada N, Maruyama A. Uptake of enzymaticallydigested hyaluronan by liver endothelial cells in vivo and in vitro. J Biomater Sci Polym Ed (2009) 20:83-97. doi:10.1163/156856208X393518

51. Armstrong SE, Bell DR. Relationship between lymph and tissue hyaluronan in skin and skeletal muscle. Am J Physiol Heart Circ Physiol (2002) 283:H2485-94. doi:10.1152/ajpheart.00385.2002

52. Culty M, Nguyen HA, Underhill CB. The hyaluronan receptor (CD44) participates in the uptake and degradation of hyaluronan. J Cell Biol (1992) 116:1055-62. doi:10.1083/jcb.116.4.1055

53. Csoka AB, Frost GI, Stern R. The six hyaluronidase-like genes in the human and mouse genomes. Matrix Biol (2001) 20:499-508. doi:10.1016/ S0945-053X(01)00172-X

54. Lepperdinger G, Strobl B, Kreil G. HYAL2, a human gene expressed in many cells, encodes a lysosomal hyaluronidase with a novel type of specificity. J Biol Chem (1998) 273:22466-70. doi:10.1074/jbc.273.35.22466

55. Harada H, Takahashi M. CD44-dependent intracellular and extracellular catabolism of hyaluronic acid by hyaluronidase-1 and -2. J Biol Chem (2007) 282:5597-607. doi:10.1074/jbc.M608358200

56. Cherr GN, Meyers SA, Yudin AI, VandeVoort CA, Myles DG, Primakoff P, et al. The PH-20 protein in cynomolgus macaque spermatozoa: identification of two different forms exhibiting hyaluronidase activity. Dev Biol (1996) 175:142-53. doi:10.1006/dbio.1996.0102

57. Bates EJ, Harper GS, Lowther DA, Preston BN. Effect of oxygen-derived reactive species on cartilage proteoglycan-hyaluronate aggregates. Biochem Int (1984) 8:629-37.

58. Karbownik MS, Nowak JZ. Hyaluronan: towards novel anti-cancer therapeutics. Pharmacol Rep (2013) 65:1056-74. doi:10.1016/S1734-1140(13) 71465-8
59. Soltés L, Kogan G, Stankovska M, Mendichi R, Rychlý J, Schiller J, et al. Degradation of high-molar-mass hyaluronan and characterization of fragments. Biomacromolecules (2007) 8:2697-705. doi:10.1021/bm070309b

60. McNeil JD, Wiebkin OW, Betts WH, Cleland LG. Depolymerisation products of hyaluronic acid after exposure to oxygen-derived free radicals. Ann Rheum Dis (1985) 44:780-9. doi:10.1136/ard.44.11.780

61. Atmuri V, Martin DC, Hemming R, Gutsol A, Byers S, Sahebjam S, et al. Hyaluronidase 3 (HYAL3) knockout mice do not display evidence of hyaluronan accumulation. Matrix Biol (2008) 27:653-60. doi:10.1016/j.matbio.2008. 07.006

62. Hemming R, Martin DC, Slominski E, Nagy JI, Halayko AJ, Pind S, et al. Mouse Hyal3 encodes a 45 - to $56-\mathrm{kDa}$ glycoprotein whose overexpression increases hyaluronidase 1 activity in cultured cells. Glycobiology (2008) 18:280-9. doi:10. 1093/glycob/cwn006

63. Natowicz MR, Short MP, Wang Y, Dickersin GR, Gebhardt MC, Rosenthal DI, et al. Clinical and biochemical manifestations of hyaluronidase deficiency. $N$ Engl J Med (1996) 335:1029-33. doi:10.1056/NEJM199610033351405

64. De la Motte C, Nigro J, Vasanji A, Rho H, Kessler S, Bandyopadhyay S, et al. Platelet-derived hyaluronidase 2 cleaves hyaluronan into fragments that trigger monocyte-mediated production of proinflammatory cytokines. Am J Pathol (2009) 174:2254-64. doi:10.2353/ajpath.2009.080831

65. Girard N, Maingonnat C, Bertrand P, Tilly H, Vannier J-P, Delpech B. Human monocytes synthesize hyaluronidase. Br J Haematol (2002) 119:199-203. doi:10.1046/j.1365-2141.2002.03733.x

66. Bot PT, Pasterkamp G, Goumans M-J, Strijder C, Moll FL, de Vries J-P, et al. Hyaluronic acid metabolism is increased in unstable plaques. Eur J Clin Invest (2010) 40:818-27. doi:10.1111/j.1365-2362.2010.02326.x

67. Chajara A, Raoudi M, Delpech B, Leroy M, Basuyau JP, Levesque H. Increased hyaluronan and hyaluronidase production and hyaluronan degradation in injured aorta of insulin-resistant rats. Arterioscler Thromb Vasc Biol (2000) 20:1480-7. doi:10.1161/01.ATV.20.6.1480

68. Chowdhury B, Hemming R, Hombach-Klonisch S, Flamion B, Triggs-Raine B. Murine hyaluronidase 2 deficiency results in extracellular hyaluronan accumulation and severe cardiopulmonary dysfunction. J Biol Chem (2013) 288:520-8. doi:10.1074/jbc.M112.393629

69. Ormiston ML, Slaughter GRD, Deng Y, Stewart DJ, Courtman DW. The enzymatic degradation of hyaluronan is associated with disease progression in experimental pulmonary hypertension. Am J Physiol Lung Cell Mol Physiol (2010) 298:L148-57. doi:10.1152/ajplung.00097.2009

70. Klagas I, Goulet S, Karakiulakis G, Zhong J, Baraket M, Black JL, et al. Decreased hyaluronan in airway smooth muscle cells from patients with asthma and COPD. Eur Respir J (2009) 34:616-28. doi:10.1183/09031936. 00070808

71. Dentener MA, Vernooy JHJ, Hendriks S, Wouters EFM. Enhanced levels of hyaluronan in lungs of patients with COPD: relationship with lung function and local inflammation. Thorax (2005) 60:114-9. doi:10.1136/thx.2003. 020842

72. Monzon ME, Fregien N, Schmid N, Falcon NS, Campos M, Casalino-Matsuda $\mathrm{SM}$, et al. Reactive oxygen species and hyaluronidase 2 regulate airway epithelial hyaluronan fragmentation. J Biol Chem (2010) 285:26126-34. doi:10.1074/ jbc.M110.135194

73. Bracke KR, Dentener MA, Papakonstantinou E, Vernooy JHJ, Demoor T, Pauwels NS, et al. Enhanced deposition of low-molecular-weight hyaluronan in lungs of cigarette smoke-exposed mice. Am J Respir Cell Mol Biol (2010) 42:753-61. doi:10.1165/rcmb.2008-0424OC

74. Eldridge L, Moldobaeva A, Wagner EM. Increased hyaluronan fragmentation during pulmonary ischemia. Am J Physiol Lung Cell Mol Physiol (2011) 301:L782-8. doi:10.1152/ajplung.00079.2011

75. Rauhala L, Hämäläinen L, Salonen P, Bart G, Tammi M, Pasonen-Seppänen $\mathrm{S}$, et al. Low dose ultraviolet $\mathrm{B}$ irradiation increases hyaluronan synthesis in epidermal keratinocytes via sequential induction of hyaluronan synthases Has1-3 mediated by p38 and Ca2+/calmodulin-dependent protein kinase II (CaMKII) signaling. J Biol Chem (2013) 288:17999-8012. doi:10.1074/jbc. M113.472530

76. Poole AR, Witter J, Roberts N, Piccolo F, Brandt R, Paquin J, et al. Inflammation and cartilage metabolism in rheumatoid arthritis. Studies of the blood markers hyaluronic acid, orosomucoid, and keratan sulfate. Arthritis Rheum (1990) 33:790-9. doi:10.1002/art.1780330605

77. Campo GM, Avenoso A, D’Ascola A, Scuruchi M, Prestipino V, Nastasi G, et al. The inhibition of hyaluronan degradation reduced pro-inflammatory 
cytokines in mouse synovial fibroblasts subjected to collagen-induced arthritis. J Cell Biochem (2012) 113:1852-67. doi:10.1002/jcb.24054

78. Bouga H, Tsouros I, Bounias D, Kyriakopoulou D, Stavropoulos MS, Papageorgakopoulou $\mathrm{N}$, et al. Involvement of hyaluronidases in colorectal cancer. BMC Cancer (2010) 10:499. doi:10.1186/1471-2407-10-499

79. Tan J-X, Wang X-Y, Su X-L, Li H-Y, Shi Y, Wang L, et al. Upregulation of HYAL1 expression in breast cancer promoted tumor cell proliferation, migration, invasion and angiogenesis. PLoS One (2011) 6:e22836. doi:10.1371/ journal.pone. 0022836

80. Delpech B, Courel MN, Maingonnat C, Chauzy C, Sesboüé R, Pratesi G. Hyaluronan digestion and synthesis in an experimental model of metastatic tumour. Histochem J (2001) 33:553-8. doi:10.1023/A:1014908009409

81. Franzmann EJ, Schroeder GL, Goodwin WJ, Weed DT, Fisher P, Lokeshwar VB. Expression of tumor markers hyaluronic acid and hyaluronidase (HYAL1) in head and neck tumors. Int J Cancer (2003) 106:438-45. doi:10.1002/ijc. 11252

82. Lokeshwar VB, Cerwinka WH, Isoyama T, Lokeshwar BL. HYAL1 hyaluronidase in prostate cancer: a tumor promoter and suppressor. Cancer Res (2005) 65:7782-9. doi:10.1158/0008-5472.CAN-05-1022

83. Delpech B, Laquerriere A, Maingonnat C, Bertrand P, Freger P. Hyaluronidase is more elevated in human brain metastases than in primary brain tumours. Anticancer Res (2002) 22:2423-7.

84. Simpson MA, Lokeshwar VB. Hyaluronan and hyaluronidase in genitourinary tumors. Front Biosci (2008) 13:5664-80. doi:10.2741/3108

85. Eissa S, Shehata H, Mansour A, Esmat M, El-Ahmady O. Detection of hyaluronidase RNA and activity in urine of schistosomal and nonschistosomal bladder cancer. Med Oncol (2012) 29:3345-51. doi:10.1007/ s12032-012-0295-8

86. Yoffou PH, Edjekouane L, Meunier L, Tremblay A, Provencher DM, MesMasson A-M, et al. Subtype specific elevated expression of hyaluronidase-1 (HYAL-1) in epithelial ovarian cancer. PLoS One (2011) 6:e20705. doi:10.1371/ journal.pone.0020705

87. Nykopp TK, Rilla K, Tammi MI, Tammi RH, Sironen R, Hämäläinen K, et al. Hyaluronan synthases (HAS1-3) and hyaluronidases (HYAL1-2) in the accumulation of hyaluronan in endometrioid endometrial carcinoma. $B M C$ Cancer (2010) 10:512. doi:10.1186/1471-2407-10-512

88. Frost GI, Mohapatra G, Wong TM, Csóka AB, Gray JW, Stern R. HYAL1LUCA-1, a candidate tumor suppressor gene on chromosome 3p21.3, is inactivated in head and neck squamous cell carcinomas by aberrant splicing of pre-mRNA. Oncogene (2000) 19:870-7. doi:10.1038/sj.onc.1203317

89. Zabarovsky ER, Lerman MI, Minna JD. Tumor suppressor genes on chromosome $3 \mathrm{p}$ involved in the pathogenesis of lung and other cancers. Oncogene (2002) 21:6915-35. doi:10.1038/sj.onc.1205835

90. Jacobson A, Rahmanian M, Rubin K, Heldin P. Expression of hyaluronan synthase 2 or hyaluronidase 1 differentially affect the growth rate of transplantable colon carcinoma cell tumors. Int J Cancer (2002) 102:212-9. doi:10.1002/ijc. 10683

91. Shuster S, Frost GI, Csoka AB, Formby B, Stern R. Hyaluronidase reduces human breast cancer xenografts in SCID mice. Int J Cancer (2002) 102:192-7. doi:10.1002/ijc. 10668

92. Provenzano PP, Cuevas C, Chang AE, Goel VK, Von Hoff DD, Hingorani SR. Enzymatic targeting of the stroma ablates physical barriers to treatment of pancreatic ductal adenocarcinoma. Cancer Cell (2012) 21:418-29. doi:10. 1016/j.ccr.2012.01.007

93. Bharadwaj AG, Kovar JL, Loughman E, Elowsky C, Oakley GG, Simpson MA. Spontaneous metastasis of prostate cancer is promoted by excess hyaluronan synthesis and processing. Am J Pathol (2009) 174:1027-36. doi:10.2353/ajpath. 2009.080501

94. Udabage L, Brownlee GR, Waltham M, Blick T, Walker EC, Heldin P, et al. Antisense-mediated suppression of hyaluronan synthase 2 inhibits the tumorigenesis and progression of breast cancer. Cancer Res (2005) 65:6139-50. doi:10.1158/0008-5472.CAN-04-1622

95. Coleman PJ, Scott D, Mason RM, Levick JR. Characterization of the effect of high molecular weight hyaluronan on trans-synovial flow in rabbit knees. $J$ Physiol (1999) 514(Pt 1):265-82. doi:10.1111/j.1469-7793.1999.265af.x

96. Wang T, Cheng HH, Heimbürger O, Chen C, Waniewski J, Bergström J, et al. Hyaluronan decreases peritoneal fluid absorption: effect of molecular weight and concentration of hyaluronan. Kidney Int (1999) 55:667-73. doi:10.1046/j. 1523-1755.1999.00279.x
97. Margolis RU, Margolis RK, Chang LB, Preti C. Glycosaminoglycans of brain during development. Biochemistry (1975) 14:85-8. doi:10.1021/bi00672a014

98. Matsumoto K, Li Y, Jakuba C, Sugiyama Y, Sayo T, Okuno M, et al. Conditional inactivation of Has 2 reveals a crucial role for hyaluronan in skeletal growth, patterning, chondrocyte maturation and joint formation in the developing limb. Development (2009) 136:2825-35. doi:10.1242/dev.038505

99. Camenisch TD, Spicer AP, Brehm-Gibson T, Biesterfeldt J, Augustine ML, Calabro A, et al. Disruption of hyaluronan synthase-2 abrogates normal cardiac morphogenesis and hyaluronan-mediated transformation of epithelium to mesenchyme. J Clin Invest (2000) 106:349-60. doi:10.1172/ JCI10272

100. Chopra A, Murray ME, Byfield FJ, Mendez MG, Halleluyan R, Restle DJ, et al. Augmentation of integrin-mediated mechanotransduction by hyaluronic acid. Biomaterials (2014) 35:71-82. doi:10.1016/j.biomaterials.2013.09.066

101. Travis JA, Hughes MG, Wong JM, Wagner WD, Geary RL. Hyaluronan enhances contraction of collagen by smooth muscle cells and adventitial fibroblasts: role of CD44 and implications for constrictive remodeling. Circ Res (2001) 88:77-83. doi:10.1161/01.RES.88.1.77

102. Gouëffic Y, Guilluy C, Guérin P, Patra P, Pacaud P, Loirand G. Hyaluronan induces vascular smooth muscle cell migration through RHAMM-mediated PI3K-dependent Rac activation. Cardiovasc Res (2006) 72:339-48. doi:10. 1016/j.cardiores.2006.07.017

103. Chen C-H, Wang S-S, Wei EI, Chu T-Y, Hsieh PCH. Hyaluronan enhances bone marrow cell therapy for myocardial repair after infarction. Mol Ther (2013) 21:670-9. doi:10.1038/mt.2012.268

104. Craig EA, Parker P, Camenisch TD. Size-dependent regulation of Snail2 by hyaluronan: its role in cellular invasion. Glycobiology (2009) 19:890-8. doi:10. 1093/glycob/cwp064

105. Bourguignon LYW, Wong G, Xia W, Man M-Q, Holleran WM, Elias PM. Selective matrix (hyaluronan) interaction with CD44 and RhoGTPase signaling promotes keratinocyte functions and overcomes age-related epidermal dysfunction. J Dermatol Sci (2013) 72:32-44. doi:10.1016/j.jdermsci.2013.05. 003

106. Passi A, Sadeghi P, Kawamura H, Anand S, Sato N, White LE, et al. Hyaluronan suppresses epidermal differentiation in organotypic cultures of rat keratinocytes. Exp Cell Res (2004) 296:123-34. doi:10.1016/j.yexcr.2004.01.031

107. Arnold F, Jia C, He C, Cherry GW, Carbow B, Meyer-Ingold W, et al. Hyaluronan, heterogeneity, and healing: the effects of ultrapure hyaluronan of defined molecular size on the repair of full-thickness pig skin wounds. Wound Repair Regen (1995) 3:299-310. doi:10.1046/j.1524-475X.1995.30310.x

108. Galeano M, Polito F, Bitto A, Irrera N, Campo GM, Avenoso A, et al. Systemic administration of high-molecular weight hyaluronan stimulates wound healing in genetically diabetic mice. Biochim Biophys Acta (2011) 1812:752-9. doi:10.1016/j.bbadis.2011.03.012

109. Khaing ZZ, Milman BD, Vanscoy JE, Seidlits SK, Grill RJ, Schmidt CE. High molecular weight hyaluronic acid limits astrocyte activation and scar formation after spinal cord injury. J Neural Eng (2011) 8:046033. doi:10.1088/ 1741-2560/8/4/046033

110. Ferns GA, Konneh M, Rutherford C, Woolaghan E, Anggard EE. Hyaluronan (HYAL-BV 5200) inhibits neo-intimal macrophage influx after ballooncatheter induced injury in the cholesterol-fed rabbit. Atherosclerosis (1995) 114:157-64. doi:10.1016/0021-9150(94)05479-3

111. Kothapalli D, Zhao L, Hawthorne EA, Cheng Y, Lee E, Puré E, et al. Hyaluronan and CD44 antagonize mitogen-dependent cyclin D1 expression in mesenchymal cells. J Cell Biol (2007) 176:535-44. doi:10.1083/jcb.200611058

112. Vigetti D, Rizzi M, Moretto P, Deleonibus S, Dreyfuss JM, Karousou E, et al. Glycosaminoglycans and glucose prevent apoptosis in 4-methylumbelliferonetreated human aortic smooth muscle cells. J Biol Chem (2011) 286:34497-503. doi:10.1074/jbc.M111.266312

113. Liu Y-Y, Lee C-H, Dedaj R, Zhao H, Mrabat H, Sheidlin A, et al. Highmolecular-weight hyaluronan - a possible new treatment for sepsis-induced lung injury: a preclinical study in mechanically ventilated rats. Crit Care (2008) 12:R102. doi:10.1186/cc6982

114. Nakamura K, Yokohama S, Yoneda M, Okamoto S, Tamaki Y, Ito T, et al. High, but not low, molecular weight hyaluronan prevents T-cell-mediated liver injury by reducing proinflammatory cytokines in mice. J Gastroenterol (2004) 39:346-54. doi:10.1007/s00535-003-1301-x

115. Fuchs K, Hippe A, Schmaus A, Homey B, Sleeman JP, Orian-Rousseau V. Opposing effects of high- and low-molecular weight hyaluronan on 
CXCL12-induced CXCR4 signaling depend on CD44. Cell Death Dis (2013) 4:e819. doi:10.1038/cddis.2013.364

116. Asari A, Kanemitsu T, Kurihara H. Oral administration of high molecular weight hyaluronan $(900 \mathrm{kDa})$ controls immune system via toll-like receptor 4 in the intestinal epithelium. J Biol Chem (2010) 285:24751-8. doi:10.1074/ jbc.M110.104950

117. Schommer NN, Muto J, Nizet V, Gallo RL. Hyaluronan breakdown contributes to immune defense against group A Streptococcus. J Biol Chem (2014) 289:26914-21. doi:10.1074/jbc.M114.575621

118. Mueller BM, Schraufstatter IU, Goncharova V, Povaliy T, DiScipio R, Khaldoyanidi SK. Hyaluronan inhibits postchemotherapy tumor regrowth in a colon carcinoma xenograft model. Mol Cancer Ther (2010) 9:3024-32. doi:10. 1158/1535-7163.MCT-10-0529

119. Chang C-C, Hsieh M-S, Liao S-T, Chen Y-H, Cheng C-W, Huang P-T, et al. Hyaluronan regulates PPAR $\gamma$ and inflammatory responses in IL-1 $\beta$ stimulated human chondrosarcoma cells, a model for osteoarthritis. Carbohydr Polym (2012) 90:1168-75. doi:10.1016/j.carbpol.2012.06.071

120. Berdiaki A, Nikitovic D, Tsatsakis A, Katonis P, Karamanos NK, Tzanakakis GN. bFGF induces changes in hyaluronan synthase and hyaluronidase isoform expression and modulates the migration capacity of fibrosarcoma cells. Biochim Biophys Acta (2009) 1790:1258-65. doi:10.1016/j.bbagen.2009. 06.013

121. Chanmee T, Ontong P, Mochizuki N, Kongtawelert P, Konno K, Itano $\mathrm{N}$. Excessive hyaluronan production promotes acquisition of cancer stem cell signatures through the coordinated regulation of twist and the transforming growth factor $\beta$ (TGF- $\beta$ )-Snail signaling axis. J Biol Chem (2014) 289:26038-56. doi:10.1074/jbc.M114.564120

122. Termeer CC, Hennies J, Voith U, Ahrens T, Weiss JM, Prehm P, et al. Oligosaccharides of hyaluronan are potent activators of dendritic cells. J Immunol (2000) 165:1863-70. doi:10.4049/jimmunol.165.4.1863

123. Termeer C, Benedix F, Sleeman J, Fieber C, Voith U, Ahrens T, et al. Oligosaccharides of hyaluronan activate dendritic cells via toll-like receptor 4. J Exp Med (2002) 195:99-111. doi:10.1084/jem.20001858

124. Tabata T, Mine S, Okada Y, Tanaka Y. Low molecular weight hyaluronan increases the uptaking of oxidized LDL into monocytes. Endocr $J$ (2007) 54:685-93. doi:10.1507/endocri.K05-120

125. Cui X, Xu H, Zhou S, Zhao T, Liu A, Guo X, et al. Evaluation of angiogenic activities of hyaluronan oligosaccharides of defined minimum size. Life Sci (2009) 85:573-7. doi:10.1016/j.lfs.2009.08.010

126. Ibrahim S, Ramamurthi A. Hyaluronic acid cues for functional endothelialization of vascular constructs. J Tissue Eng Regen Med (2008) 2:22-32. doi:10. $1002 /$ term.61

127. Taylor KR, Trowbridge JM, Rudisill JA, Termeer CC, Simon JC, Gallo RL. Hyaluronan fragments stimulate endothelial recognition of injury through TLR4. J Biol Chem (2004) 279:17079-84. doi:10.1074/jbc.M310859200

128. McCourt PA, Ek B, Forsberg N, Gustafson S. Intercellular adhesion molecule-1 is a cell surface receptor for hyaluronan. J Biol Chem (1994) 269:30081-4.

129. Deed R, Rooney P, Kumar P, Norton JD, Smith J, Freemont AJ, et al. Early-response gene signalling is induced by angiogenic oligosaccharides of hyaluronan in endothelial cells. Inhibition by non-angiogenic, highmolecular-weight hyaluronan. Int J Cancer (1997) 71:251-6. doi:10.1002/ (SICI) 1097-0215(19970410)71:2<251::AID-IJC21>3.0.CO;2-J

130. Campo GM, Avenoso A, D’Ascola A, Scuruchi M, Prestipino V, Calatroni A, et al. Hyaluronan in part mediates IL-1beta-induced inflammation in mouse chondrocytes by up-regulating CD44 receptors. Gene (2012) 494:24-35. doi:10.1016/j.gene.2011.11.064

131. Sylvester A, Sivaraman B, Deb P, Ramamurthi A. Nanoparticles for localized delivery of hyaluronan oligomers towards regenerative repair of elastic matrix. Acta Biomater (2013) 9:9292-302. doi:10.1016/j.actbio.2013.07.032

132. Tolg C, Telmer P, Turley E. Specific sizes of hyaluronan oligosaccharides stimulate fibroblast migration and excisional wound repair. PLoS One (2014) 9:e88479. doi:10.1371/journal.pone.0088479

133. Gao F, Liu Y, He Y, Yang C, Wang Y, Shi X, et al. Hyaluronan oligosaccharides promote excisional wound healing through enhanced angiogenesis. Matrix Biol (2010) 29:107-16. doi:10.1016/j.matbio.2009.11.002

134. Kothapalli CR, Taylor PM, Smolenski RT, Yacoub MH, Ramamurthi A. Transforming growth factor beta 1 and hyaluronan oligomers synergistically enhance elastin matrix regeneration by vascular smooth muscle cells. Tissue Eng Part A (2009) 15:501-11. doi:10.1089/ten.tea.2008.0040
135. Chajara A, Raoudi M, Delpech B, Levesque H. Inhibition of arterial cells proliferation in vivo in injured arteries by hyaluronan fragments. Atherosclerosis (2003) 171:15-9. doi:10.1016/S0021-9150(03)00303-4

136. Xu H, Ito T, Tawada A, Maeda $\mathrm{H}$, Yamanokuchi H, Isahara K, et al. Effect of hyaluronan oligosaccharides on the expression of heat shock protein 72. J Biol Chem (2002) 277:17308-14. doi:10.1074/jbc.M112371200

137. Selbi W, de la Motte CA, Hascall VC, Day AJ, Bowen T, Phillips AO. Characterization of hyaluronan cable structure and function in renal proximal tubular epithelial cells. Kidney Int (2006) 70:1287-95. doi:10.1038/sj.ki.5001760

138. Lauer ME, Glant TT, Mikecz K, DeAngelis PL, Haller FM, Husni ME, et al. Irreversible heavy chain transfer to hyaluronan oligosaccharides by tumor necrosis factor-stimulated gene-6. J Biol Chem (2013) 288:205-14. doi:10. 1074/jbc.M112.403998

139. Bourguignon LYW, Wong G, Earle CA, Xia W. Interaction of low molecular weight hyaluronan with $\mathrm{CD} 44$ and toll-like receptors promotes the actin filament-associated protein 110-actin binding and MyD88-NFKB signaling leading to proinflammatory cytokine/chemokine production and breast tumor invasion. Cytoskeleton (Hoboken) (2011) 68:671-93. doi:10.1002/cm.20544

140. Fieber C, Baumann P, Vallon R, Termeer C, Simon JC, Hofmann M, et al. Hyaluronan-oligosaccharide-induced transcription of metalloproteases. J Cell Sci (2004) 117:359-67. doi:10.1242/jcs.00831

141. Toole BP, Ghatak S, Misra S. Hyaluronan oligosaccharides as a potential anticancer therapeutic. Curr Pharm Biotechnol (2008) 9:249-52. doi:10.2174/ 138920108785161569

142. Zeng C, Toole BP, Kinney SD, Kuo JW, Stamenkovic I. Inhibition of tumor growth in vivo by hyaluronan oligomers. Int J Cancer (1998) 77:396-401. doi:10.1002/(SICI)1097-0215(19980729)77:3<396::AID-IJC15>3.3.CO;2-W

143. Ghatak S, Misra S, Toole BP. Hyaluronan oligosaccharides inhibit anchorageindependent growth of tumor cells by suppressing the phosphoinositide 3 kinase/Akt cell survival pathway. J Biol Chem (2002) 277:38013-20. doi:10. 1074/jbc.M202404200

144. Wiranowska M, Ladd S, Moscinski LC, Hill B, Haller E, Mikecz K, et al. Modulation of hyaluronan production by CD44 positive glioma cells. Int $J$ Cancer (2010) 127:532-42. doi:10.1002/ijc.25085

145. Gilg AG, Tye SL, Tolliver LB, Wheeler WG, Visconti RP, Duncan JD, et al. Targeting hyaluronan interactions in malignant gliomas and their drug-resistant multipotent progenitors. Clin Cancer Res (2008) 14:1804-13. doi:10.1158/ 1078-0432.CCR-07-1228

146. Kujawa MJ, Carrino DA, Caplan AI. Substrate-bonded hyaluronic acid exhibits a size-dependent stimulation of chondrogenic differentiation of stage 24 limb mesenchymal cells in culture. Dev Biol (1986) 114:519-28. doi:10.1016/ 0012-1606(86)90214-9

147. Park JU, Tsuchiya T. Increase in gap junctional intercellular communication by high molecular weight hyaluronic acid associated with fibroblast growth factor 2 and keratinocyte growth factor production in normal human dermal fibroblasts. Tissue Eng (2002) 8:419-27. doi:10.1089/107632702760184682

148. Ghazi K, Deng-Pichon U, Warnet J-M, Rat P. Hyaluronan fragments improve wound healing on in vitro cutaneous model through P2X7 purinoreceptor basal activation: role of molecular weight. PLoS One (2012) 7:e48351. doi:10. 1371/journal.pone.0048351

149. Joddar B, Ramamurthi A. Fragment size- and dose-specific effects of hyaluronan on matrix synthesis by vascular smooth muscle cells. Biomaterials (2006) 27:2994-3004. doi:10.1016/j.biomaterials.2006.01.020

150. Damodarasamy M, Johnson RS, Bentov I, MacCoss MJ, Vernon RB, Reed MJ. Hyaluronan enhances wound repair and increases collagen III in aged dermal wounds. Wound Repair Regen (2014) 22:521-6. doi:10.1111/wrr.12192

151. Kaya G, Tran C, Sorg O, Hotz R, Grand D, Carraux P, et al. Hyaluronate fragments reverse skin atrophy by a CD44-dependent mechanism. PLoS Med (2006) 3:e493. doi:10.1371/journal.pmed.0030493

152. Trabucchi E, Pallotta S, Morini M, Corsi F, Franceschini R, Casiraghi A, et al. Low molecular weight hyaluronic acid prevents oxygen free radical damage to granulation tissue during wound healing. Int J Tissue React (2002) 24:65-71.

153. Scuri M, Abraham WM, Botvinnikova Y, Forteza R. Hyaluronic acid blocks porcine pancreatic elastase (PPE)-induced bronchoconstriction in sheep. Am J Respir Crit Care Med (2001) 164:1855-9. doi:10.1164/ajrccm.164.10.2011115

154. Cantor JO, Shteyngart B, Cerreta JM, Liu M, Armand G, Turino GM. The effect of hyaluronan on elastic fiber injury in vitro and elastase-induced airspace enlargement in vivo. Proc Soc Exp Biol Med (2000) 225:65-71. doi:10.1046/ j.1525-1373.2000.22508.x 
155. Garantziotis S, Li Z, Potts EN, Kimata K, Zhuo L, Morgan DL, et al. Hyaluronan mediates ozone-induced airway hyperresponsiveness in mice. J Biol Chem (2009) 284:11309-17. doi:10.1074/jbc.M802400200

156. Leu S-W, Shi L, Xu C, Zhao Y, Liu B, Li Y, et al. TLR4 through IFN- $\beta$ promotes low molecular mass hyaluronan-induced neutrophil apoptosis. J Immunol (2011) 186:556-62. doi:10.4049/jimmunol.1001630

157. Onoda M, Nakaseko C, Yokota A, Saito Y. Ligation of CD44 with lowmolecular-weight hyaluronan and a monoclonal antibody leads to inhibition of drug-induced apoptosis in a human myeloid cell line. Hematology (2009) 14:213-9. doi:10.1179/102453309X426236

158. Wolf D, Schümann J, Koerber K, Kiemer AK, Vollmar AM, Sass G, et al. Lowmolecular-weight hyaluronic acid induces nuclear factor-kappaB-dependent resistance against tumor necrosis factor alpha-mediated liver injury in mice. Hepatology (2001) 34:535-47. doi:10.1053/jhep.2001.27218

159. Hill DR, Kessler SP, Rho HK, Cowman MK, de la Motte CA. Specific-sized hyaluronan fragments promote expression of human $\beta$-defensin 2 in intestinal epithelium. J Biol Chem (2012) 287:30610-24. doi:10.1074/jbc.M112.356238

160. Collins SL, Black KE, Chan-Li Y, Ahn Y-H, Cole PA, Powell JD, et al. Hyaluronan fragments promote inflammation by down-regulating the antiinflammatory A2a receptor. Am J Respir Cell Mol Biol (2011) 45:675-83. doi:10.1165/rcmb.2010-0387OC

161. Pandey MS, Baggenstoss BA, Washburn J, Harris EN, Weigel PH. The hyaluronan receptor for endocytosis (HARE) activates NF- $\kappa \mathrm{B}$-mediated gene expression in response to $40-400-\mathrm{kDa}$, but not smaller or larger, hyaluronans. J Biol Chem (2013) 288:14068-79. doi:10.1074/jbc.M112.442889

162. Scheibner KA, Lutz MA, Boodoo S, Fenton MJ, Powell JD, Horton MR. Hyaluronan fragments act as an endogenous danger signal by engaging TLR2. J Immunol (2006) 177:1272-81. doi:10.4049/jimmunol.177.2.1272

163. Schraufstatter I, Serobyan N, DiScipio R, Feofanova N, Orlovskaya I, Khaldoyanidi SK. Hyaluronan stimulates mobilization of mature hematopoietic cells but not hematopoietic progenitors. J Stem Cells (2009) 4:191-202. doi:jsc.2010. 4.4.191

164. Lyle DB, Breger JC, Baeva LF, Shallcross JC, Durfor CN, Wang NS, et al. Low molecular weight hyaluronic acid effects on murine macrophage nitric oxide production. J Biomed Mater Res A (2010) 94:893-904. doi:10.1002/jbm. a. 32760

165. Hodge-Dufour J, Noble PW, Horton MR, Bao C, Wysoka M, Burdick MD, et al. Induction of IL-12 and chemokines by hyaluronan requires adhesiondependent priming of resident but not elicited macrophages. J Immunol (1997) 159:2492-500

166. McKee CM, Penno MB, Cowman M, Burdick MD, Strieter RM, Bao C, et al. Hyaluronan (HA) fragments induce chemokine gene expression in alveolar macrophages. The role of HA size and CD44. J Clin Invest (1996) 98:2403-13. doi:10.1172/JCI119054

167. Sokolowska M, Chen L-Y, Eberlein M, Martinez-Anton A, Liu Y, Alsaaty S, et al. Low molecular weight hyaluronan activates cytosolic phospholipase A2 $\alpha$ and eicosanoid production in monocytes and macrophages. J Biol Chem (2014) 289:4470-88. doi:10.1074/jbc.M113.515106

168. Kuang D-M, Wu Y, Chen N, Cheng J, Zhuang S-M, Zheng L. Tumor-derived hyaluronan induces formation of immunosuppressive macrophages through transient early activation of monocytes. Blood (2007) 110:587-95. doi:10.1182/ blood-2007-01-068031

169. Boodoo S, Spannhake EW, Powell JD, Horton MR. Differential regulation of hyaluronan-induced IL-8 and IP-10 in airway epithelial cells. Am J Physiol Lung Cell Mol Physiol (2006) 291:L479-86. doi:10.1152/ajplung.00518.2005

170. Ochoa CD, Garg HG, Hales CA, Quinn DA. Low molecular weight hyaluronan, via AP-1 and NF- $\mathrm{KB}$ signalling, induces IL-8 in transformed bronchial epithelial cells. Swiss Med Wkly (2011) 141:w13255. doi:10.4414/smw.2011. 13255

171. Campo GM, Avenoso A, Campo S, D’Ascola A, Traina P, Calatroni A. Differential effect of molecular size HA in mouse chondrocytes stimulated with PMA. Biochim Biophys Acta (2009) 1790:1353-67. doi:10.1016/j.bbagen.2009.07.003

172. Campo GM, Avenoso A, Campo S, D’Ascola A, Nastasi G, Calatroni A. Molecular size hyaluronan differently modulates toll-like receptor-4 in LPSinduced inflammation in mouse chondrocytes. Biochimie (2010) 92:204-15. doi:10.1016/j.biochi.2009.10.006

173. Kashima Y, Takahashi M, Shiba Y, Itano N, Izawa A, Koyama J, et al. Crucial role of hyaluronan in neointimal formation after vascular injury. PLoS One (2013) 8:e58760. doi:10.1371/journal.pone.0058760
174. Rockey DC, Chung JJ, McKee CM, Noble PW. Stimulation of inducible nitric oxide synthase in rat liver by hyaluronan fragments. Hepatology (1998) 27:86-92. doi:10.1002/hep.510270115

175. Kothapalli D, Flowers J, Xu T, Puré E, Assoian RK. Differential activation of ERK and Rac mediates the proliferative and anti-proliferative effects of hyaluronan and CD44. J Biol Chem (2008) 283:31823-9. doi:10.1074/jbc. M802934200

176. Zhao H, Leu S-W, Shi L, Dedaj R, Zhao G, Garg HG, et al. TLR4 is a negative regulator in noninfectious lung inflammation. J Immunol (2010) 184:5308-14. doi:10.4049/jimmunol.1000009

177. Ke C, Wang D, Sun Y, Qiao D, Ye H, Zeng X. Immunostimulatory and antiangiogenic activities of low molecular weight hyaluronic acid. Food Chem Toxicol (2013) 58:401-7. doi:10.1016/j.fct.2013.05.032

178. Thaete LG, Qu X-W, Jilling T, Crawford SE, Fitchev P, Hirsch E, et al. Impact of toll-like receptor 4 deficiency on the response to uterine ischemia/reperfusion in mice. Reproduction (2013) 145:517-26. doi:10.1530/REP-12-0433

179. Kouvidi K, Berdiaki A, Nikitovic D, Katonis P, Afratis N, Hascall VC, et al. Role of receptor for hyaluronic acid-mediated motility (RHAMM) in low molecular weight hyaluronan (LMWHA)-mediated fibrosarcoma cell adhesion. J Biol Chem (2011) 286:38509-20. doi:10.1074/jbc.M111.275875

180. Tofuku K, Yokouchi M, Murayama T, Minami S, Komiya S. HAS3-related hyaluronan enhances biological activities necessary for metastasis of osteosarcoma cells. Int J Oncol (2006) 29:175-83. doi:10.3892/ijo.29.1.1.175

181. Fitzgerald KA, Bowie AG, Skeffington BS, O’Neill LA. Ras, protein kinase C zeta, and I kappa B kinases 1 and 2 are downstream effectors of CD44 during the activation of NF-kappa B by hyaluronic acid fragments in T-24 carcinoma cells. J Immunol (2000) 164:2053-63. doi:10.4049/jimmunol.164.4.2053

182. Yang T, Witham TF, Villa L, Erff M, Attanucci J, Watkins S, et al. Gliomaassociated hyaluronan induces apoptosis in dendritic cells via inducible nitric oxide synthase: implications for the use of dendritic cells for therapy of gliomas. Cancer Res (2002) 62:2583-91.

183. Alaniz L, Rizzo M, Malvicini M, Jaunarena J, Avella D, Atorrasagasti C, et al. Low molecular weight hyaluronan inhibits colorectal carcinoma growth by decreasing tumor cell proliferation and stimulating immune response. Cancer Lett (2009) 278:9-16. doi:10.1016/j.canlet.2008.12.029

184. Alaniz L, Rizzo M, Garcia MG, Piccioni F, Aquino JB, Malvicini M, et al. Low molecular weight hyaluronan preconditioning of tumor-pulsed dendritic cells increases their migratory ability and induces immunity against murine colorectal carcinoma. Cancer Immunol Immunother (2011) 60:1383-95. doi:10. 1007/s00262-011-1036-0

185. Cichy J, Puré E. The liberation of CD44. J Cell Biol (2003) 161:839-43. doi:10. 1083/jcb.200302098

186. Cichy J, Kulig P, Puré E. Regulation of the release and function of tumor cellderived soluble CD44. Biochim Biophys Acta (2005) 1745:59-64. doi:10.1016/ j.bbamcr.2005.02.006

187. Lesley J, Hyman R, Kincade PW. CD44 and its interaction with extracellular matrix. Adv Immunol (1993) 54:271-335. doi:10.1016/S0065-2776(08) 60537-4

188. Camp RL, Kraus TA, Puré E. Variations in the cytoskeletal interaction and posttranslational modification of the CD44 homing receptor in macrophages. J Cell Biol (1991) 115:1283-92. doi:10.1083/jcb.115.5.1283

189. Jiang H, Peterson RS, Wang W, Bartnik E, Knudson CB, Knudson W. A requirement for the CD44 cytoplasmic domain for hyaluronan binding, pericellular matrix assembly, and receptor-mediated endocytosis in COS-7 cells. $J$ Biol Chem (2002) 277:10531-8. doi:10.1074/jbc.M108654200

190. Puré E, Camp RL, Peritt D, Panettieri RA, Lazaar AL, Nayak S. Defective phosphorylation and hyaluronate binding of CD44 with point mutations in the cytoplasmic domain. J Exp Med (1995) 181:55-62. doi:10.1084/jem.181.1.55

191. Katoh S, Zheng Z, Oritani K, Shimozato T, Kincade PW. Glycosylation of CD44 negatively regulates its recognition of hyaluronan. J Exp Med (1995) 182:419-29. doi:10.1084/jem.182.2.419

192. Gasbarri A, Del Prete F, Girnita L, Martegani MP, Natali PG, Bartolazzi A. CD44s adhesive function spontaneous and PMA-inducible CD44 cleavage are regulated at post-translational level in cells of melanocytic lineage. Melanoma Res (2003) 13:325-37. doi:10.1097/01.cmr.0000056256.56735.0f

193. Ruffell B, Poon GFT, Lee SSM, Brown KL, Tjew S-L, Cooper J, et al. Differential use of chondroitin sulfate to regulate hyaluronan binding by receptor CD44 in inflammatory and interleukin 4-activated macrophages. J Biol Chem (2011) 286:19179-90. doi:10.1074/jbc.M110.200790 
194. Schmits R, Filmus J, Gerwin N, Senaldi G, Kiefer F, Kundig T, et al. CD44 regulates hematopoietic progenitor distribution, granuloma formation, and tumorigenicity. Blood (1997) 90:2217-33.

195. Teder P, Vandivier RW, Jiang D, Liang J, Cohn L, Puré E, et al. Resolution of lung inflammation by CD44. Science (2002) 296:155-8. doi:10.1126/science. 1069659

196. Cuff CA, Kothapalli D, Azonobi I, Chun S, Zhang Y, Belkin R, et al. The adhesion receptor $\mathrm{CD} 44$ promotes atherosclerosis by mediating inflammatory cell recruitment and vascular cell activation. J Clin Invest (2001) 108:1031-40. doi:10.1172/JCI12455

197. Zhao L, Lee E, Zukas AM, Middleton MK, Kinder M, Acharya PS, et al. CD44 expressed on both bone marrow-derived and non-bone marrow-derived cells promotes atherogenesis in ApoE-deficient mice. Arterioscler Thromb Vasc Biol (2008) 28:1283-9. doi:10.1161/ATVBAHA.108.165753

198. Zhao L, Hall JA, Levenkova N, Lee E, Middleton MK, Zukas AM, et al. CD44 regulates vascular gene expression in a proatherogenic environment. Arterioscler Thromb Vasc Biol (2007) 27:886-92. doi:10.1161/01.ATV.0000259362. 10882.c5

199. Nandi A, Estess P, Siegelman MH. Hyaluronan anchoring and regulation on the surface of vascular endothelial cells is mediated through the functionally active form of CD44. J Biol Chem (2000) 275:14939-48. doi:10.1074/jbc.275. 20.14939

200. Johnson P, Maiti A, Brown KL, Li R. A role for the cell adhesion molecule CD44 and sulfation in leukocyte-endothelial cell adhesion during an inflammatory response? Biochem Pharmacol (2000) 59:455-65. doi:10.1016/S0006-2952(99) 00266-X

201. Mummert ME. Immunologic roles of hyaluronan. Immunol Res (2005) 31:189-206. doi:10.1385/IR:31:3:189

202. Mummert ME, Mohamadzadeh M, Mummert DI, Mizumoto N, Takashima A. Development of a peptide inhibitor of hyaluronan-mediated leukocyte trafficking. J Exp Med (2000) 192:769-79. doi:10.1084/jem.192.6.769

203. Singleton PA, Salgia R, Moreno-Vinasco L, Moitra J, Sammani S, Mirzapoiazova $\mathrm{T}$, et al. CD44 regulates hepatocyte growth factor-mediated vascular integrity. Role of c-Met, Tiam1/Rac1, dynamin 2, and cortactin. J Biol Chem (2007) 282:30643-57. doi:10.1074/jbc.M702573200

204. Singleton PA, Mirzapoiazova T, Guo Y, Sammani S, Mambetsariev N, Lennon FE, et al. High-molecular-weight hyaluronan is a novel inhibitor of pulmonary vascular leakiness. Am J Physiol Lung Cell Mol Physiol (2010) 299:L639-51. doi:10.1152/ajplung.00405.2009

205. Harada N, Mizoi T, Kinouchi M, Hoshi K, Ishii S, Shiiba K, et al. Introduction of antisense CD44S CDNA down-regulates expression of overall CD44 isoforms and inhibits tumor growth and metastasis in highly metastatic colon carcinoma cells. Int J Cancer (2001) 91:67-75. doi:10.1002/1097-0215(20010101) 91:1<67::AID-IJC1011>3.0.CO;2-D

206. Mummert ME, Mummert DI, Ellinger L, Takashima A. Functional roles of hyaluronan in B16-F10 melanoma growth and experimental metastasis in mice. Mol Cancer Ther (2003) 2:295-300.

207. Godar S, Ince TA, Bell GW, Feldser D, Donaher JL, Bergh J, et al. Growth-inhibitory and tumor- suppressive functions of p53 depend on its repression of CD44 expression. Cell (2008) 134:62-73. doi:10.1016/j.cell.2008. 06.006

208. Huang Q, Gumireddy K, Schrier M, le Sage C, Nagel R, Nair S, et al. The microRNAs miR-373 and miR-520c promote tumour invasion and metastasis. Nat Cell Biol (2008) 10:202-10. doi:10.1038/ncb1681

209. Afify A, Purnell P, Nguyen L. Role of CD44s and CD44v6 on human breast cancer cell adhesion, migration, and invasion. Exp Mol Pathol (2009) 86:95-100. doi:10.1016/j.yexmp.2008.12.003

210. Yang C, Cao M, Liu H, He Y, Xu J, Du Y, et al. The high and low molecular weight forms of hyaluronan have distinct effects on CD44 clustering. J Biol Chem (2012) 287:43094-107. doi:10.1074/jbc.M112.349209

211. Qhattal HSS, Liu X. Characterization of CD44-mediated cancer cell uptake and intracellular distribution of hyaluronan-grafted liposomes. Mol Pharm (2011) 8:1233-46. doi:10.1021/mp2000428

212. Pusch A, Boeckenhoff A, Glaser T, Kaminski T, Kirfel G, Hans M, et al. CD44 and hyaluronan promote invasive growth of B35 neuroblastoma cells into the brain. Biochim Biophys Acta (2010) 1803:261-74. doi:10.1016/j.bbamcr.2009. 12.003

213. Sugahara KN, Hirata T, Tanaka T, Ogino S, Takeda M, Terasawa H, et al. Chondroitin sulfate E fragments enhance CD44 cleavage and CD44-dependent motility in tumor cells. Cancer Res (2008) 68:7191-9. doi:10.1158/0008-5472. CAN-07-6198

214. Rutnam ZJ, Yang BB. The non-coding 3' UTR of CD44 induces metastasis by regulating extracellular matrix functions. J Cell Sci (2012) 125:2075-85. doi: $10.1242 /$ jcs 100818

215. Huebener P, Abou-Khamis T, Zymek P, Bujak M, Ying X, Chatila K, et al. CD44 is critically involved in infarct healing by regulating the inflammatory and fibrotic response. J Immunol (2008) 180:2625-33. doi:10.4049/jimmunol. 180.4 .2625

216. Müller J, Gorressen S, Grandoch M, Feldmann K, Kretschmer I, Lehr S, et al. Interleukin-6-dependent phenotypic modulation of cardiac fibroblasts after acute myocardial infarction. Basic Res Cardiol (2014) 109:440. doi:10.1007/ s00395-014-0440-y

217. Acharya PS, Majumdar S, Jacob M, Hayden J, Mrass P, Weninger W, et al. Fibroblast migration is mediated by CD44-dependent TGF beta activation. $J$ Cell Sci (2008) 121:1393-402. doi:10.1242/jcs.021683

218. Tolg C, Hamilton SR, Nakrieko K-A, Kooshesh F, Walton P, McCarthy JB, et al. Rhamm-/- fibroblasts are defective in CD44-mediated ERK1,2 motogenic signaling, leading to defective skin wound repair. J Cell Biol (2006) 175:1017-28. doi:10.1083/jcb.200511027

219. Wolny PM, Banerji S, Gounou C, Brisson AR, Day AJ, Jackson DG, et al. Analysis of CD44-hyaluronan interactions in an artificial membrane system: insights into the distinct binding properties of high and low molecular weight hyaluronan. J Biol Chem (2010) 285:30170-80. doi:10.1074/jbc.M110. 137562

220. Haserodt S, Aytekin M, Dweik RA. A comparison of the sensitivity, specificity, and molecular weight accuracy of three different commercially available hyaluronan ELISA-like assays. Glycobiology (2011) 21:175-83. doi:10.1093/ glycob/cwq145

221. Skandalis SS, Stylianou M, Vynios DH, Papageorgakopoulou N, Theocharis DA. The structural and compositional changes of glycosaminoglycans are closely associated with tissue type in human laryngeal cancer. Biochimie (2007) 89:1573-80. doi:10.1016/j.biochi.2007.07.006

222. Hampson IN, Gallagher JT. Separation of radiolabelled glycosaminoglycan oligosaccharides by polyacrylamide-gel electrophoresis. Biochem J (1984) 221:697-705.

223. Bhilocha S, Amin R, Pandya M, Yuan H, Tank M, LoBello J, et al. Agarose and polyacrylamide gel electrophoresis methods for molecular mass analysis of 5 to 500-kDa hyaluronan. Anal Biochem (2011) 417:41-9. doi:10.1016/j.ab.2011 05.026

224. Cowman MK, Chen CC, Pandya M, Yuan H, Ramkishun D, LoBello J, et al Improved agarose gel electrophoresis method and molecular mass calculation for high molecular mass hyaluronan. Anal Biochem (2011) 417:50-6. doi:10. 1016/j.ab.2011.05.023

225. Kamada H, Masuda K, D’Souza AL, Lenz ME, Pietryla D, Otten L, et al. Agerelated differences in the accumulation and size of hyaluronan in alginate culture. Arch Biochem Biophys (2002) 408:192-9. doi:10.1016/S0003-9861(02) 00543-X

226. Lee HG, Cowman MK. An agarose gel electrophoretic method for analysis of hyaluronan molecular weight distribution. Anal Biochem (1994) 219:278-87. doi:10.1006/abio.1994.1267

227. Lauer ME, Mukhopadhyay D, Fulop C, de la Motte CA, Majors AK, Hascall VC. Primary murine airway smooth muscle cells exposed to poly $(\mathrm{I}, \mathrm{C})$ or tunicamycin synthesize a leukocyte-adhesive hyaluronan matrix. J Biol Chem (2009) 284:5299-312. doi:10.1074/jbc.M807965200

228. Malm L, Hellman U, Larsson G. Size determination of hyaluronan using a gas-phase electrophoretic mobility molecular analysis. Glycobiology (2012) 22:7-11. doi:10.1093/glycob/cwr096

229. Hellman U, Malm L, Ma L-P, Larsson G, Mörner S, Fu M, et al. Growth factor PDGF-BB stimulates cultured cardiomyocytes to synthesize the extracellular matrix component hyaluronan. PLoS One (2010) 5:e14393. doi:10.1371/ journal.pone.0014393

230. Kang DY, Kim W-S, Heo IS, Park YH, Lee S. Extraction of hyaluronic acid (HA) from rooster comb and characterization using flow field-flow fractionation (FlFFF) coupled with multiangle light scattering (MALS). J Sep Sci (2010) 33:3530-6. doi:10.1002/jssc.201000478

231. DeAngelis PL. Monodisperse hyaluronan polymers: synthesis and potential applications. Curr Pharm Biotechnol (2008) 9:246-8. doi:10.2174/ 138920108785161550 
232. Boeriu CG, Springer J, Kooy FK, van den Broek LAM, Eggink G. Production methods for hyaluronan. Int J Carbohydr Chem (2013) 2013:14. doi:10.1155/ 9160

233. Marcellin E, Steen JA, Nielsen LK. Insight into hyaluronic acid molecular weight control. Appl Microbiol Biotechnol (2014) 98:6947-56. doi:10.1007/ s00253-014-5853-x

234. Iannitti T, Lodi D, Palmieri B. Intra-articular injections for the treatment of osteoarthritis: focus on the clinical use of hyaluronic acid. Drugs $R D$ (2011) 11:13-27. doi:10.2165/11539760-000000000-00000

235. Estes JM, Adzick NS, Harrison MR, Longaker MT, Stern R. Hyaluronate metabolism undergoes an ontogenic transition during fetal development: implications for scar-free wound healing. J Pediatr Surg (1993) 28:1227-31. doi:10.1016/S0022-3468(05)80303-3

236. Armstrong SE, Bell DR. Measurement of high-molecular-weight hyaluronan in solid tissue using agarose gel electrophoresis. Anal Biochem (2002) 308:255-64. doi:10.1016/S0003-2697(02)00239-7

237. Meyer FA, Preston BN, Lowther DA. Isolation and properties of hyaluronic acid from bovine heart valves. Biochem J (1969) 113:559-63.

238. Radhakrishnamurthy B, Dalferes ER, Vijayagopal P, Berenson GS. Determination of mulecular-weight distribution of aorta glycosaminoglycans by automated gel filtration. J Chromatogr (1980) 192:307-14. doi:10.1016/ S0021-9673(80)80005-7

239. Chajara A, Raoudi M, Delpech B, Levesque $\mathrm{H}$. The fibroproliferative response of arterial smooth muscle cells to balloon catheter injury is associated with increased hyaluronidase production and hyaluronan degradation. Atherosclerosis (2001) 157:293-300. doi:10.1016/S0021-9150(00)00727-9

240. Hamilton SR, Veiseh M, Tölg C, Tirona R, Richardson J, Brown R, et al. Pharmacokinetics and pharmacodynamics of hyaluronan infused into healthy human volunteers. Open Drug Metab J (2009) 3:43-55. doi:10.2174/ 1874073100903010043

241. Gustafson S. The influence of sulfated polysaccharides on the circulating levels of hyaluronan. Glycobiology (1997) 7:1209-14. doi:10.1093/glycob/7.8. 1209

242. Sallisalmi M, Tenhunen J, Kultti A, Tammi M, Pettilä V. Plasma hyaluronan and hemorheology in patients with septic shock: a clinical and experimental study. Clin Hemorheol Microcirc (2014) 56:133-44. doi:10.3233/ $\mathrm{CH}-131677$

243. Tengblad A, Laurent UB, Lilja K, Cahill RN, Engström-Laurent A, Fraser JR, et al. Concentration and relative molecular mass of hyaluronate in lymph and blood. Biochem J (1986) 236:521-5.

244. Sasaki Y, Uzuki M, Nohmi K, Kitagawa H, Kamataki A, Komagamine M, et al. Quantitative measurement of serum hyaluronic acid molecular weight in rheumatoid arthritis patients and the role of hyaluronidase. Int J Rheum Dis (2011) 14:313-9. doi:10.1111/j.1756-185X.2011.01683.x

245. Murawaki Y, Ikuta Y, Idobe Y, Koda M, Kawasaki H. Molecular weight of hyaluronate in the serum of patients with chronic liver disease. Res Commun Mol Pathol Pharmacol (1998) 99:207-16.

246. Armstrong SE, Bell DR. Ischemia-reperfusion does not cause significant hyaluronan depolymerization in skeletal muscle. Microvasc Res (2002) 64:353-62. doi:10.1006/mvre.2002.2437

247. Laurent UB, Laurent TC, Hellsing LK, Persson L, Hartman M, Lilja K. Hyaluronan in human cerebrospinal fluid. Acta Neurol Scand (1996) 94:194-206. doi:10.1111/j.1600-0404.1996.tb07052.x

248. Bugiani M, Postma N, Polder E, Dieleman N, Scheffer PG, Sim FJ, et al. Hyaluronan accumulation and arrested oligodendrocyte progenitor maturation in vanishing white matter disease. Brain (2013) 136:209-22. doi:10.1093/ brain/aws 320

249. Theocharis DA, Skandalis SS, Noulas AV, Papageorgakopoulou N, Theocharis $\mathrm{AD}$, Karamanos NK. Hyaluronan and chondroitin sulfate proteoglycans in the supramolecular organization of the mammalian vitreous body. Connect Tissue Res (2008) 49:124-8. doi:10.1080/03008200802148496

250. Østerholt HCD, Dannevig I, Wyckoff MH, Liao J, Akgul Y, Ramgopal M, et al. Antioxidant protects against increases in low molecular weight hyaluronan and inflammation in asphyxiated newborn pigs resuscitated with $100 \%$ oxygen. PLoS One (2012) 7:e38839. doi:10.1371/journal.pone.0038839

251. Cheng G, Swaidani S, Sharma M, Lauer ME, Hascall VC, Aronica MA. Correlation of hyaluronan deposition with infiltration of eosinophils and lymphocytes in a cockroach-induced murine model of asthma. Glycobiology (2013) 23:43-58. doi:10.1093/glycob/cws122
252. Zelko IN, Folz RJ. Extracellular superoxide dismutase attenuates release of pulmonary hyaluronan from the extracellular matrix following bleomycin exposure. FEBS Lett (2010) 584:2947-52. doi:10.1016/j.febslet.2010.05.025

253. Mascarenhas MM, Day RM, Ochoa CD, Choi W-I, Yu L, Ouyang B, et al. Low molecular weight hyaluronan from stretched lung enhances interleukin8 expression. Am J Respir Cell Mol Biol (2004) 30:51-60. doi:10.1165/rcmb. 2002-0167OC

254. Nettelbladt O, Tengblad A, Hällgren R. Lung accumulation of hyaluronan parallels pulmonary edema in experimental alveolitis. Am J Physiol (1989) 257:L379-84.

255. Motomiya M, Endo M, Arai H, Yokosawa A, Sato H, Konno K. Biochemical characterization of hyaluronic acid from a case of benign, localized, pleural mesothelioma. Am Rev Respir Dis (1975) 111:775-80.

256. Tammi R, Säämänen AM, Maibach HI, Tammi M. Degradation of newly synthesized high molecular mass hyaluronan in the epidermal and dermal compartments of human skin in organ culture. J Invest Dermatol (1991) 97:126-30. doi:10.1111/1523-1747.ep12478553

257. Sakai S, Yasuda R, Sayo T, Ishikawa O, Inoue S. Hyaluronan exists in the normal stratum corneum. J Invest Dermatol (2000) 114:1184-7. doi:10.1046/j. 1523-1747.2000.00992.x

258. Motohashi N, Nakamichi Y, Mori I, Nishikawa H, Umemoto J. Analysis by high-performance gel permeation chromatography of hyaluronic acid in animal skins and rabbit synovial fluid. J Chromatogr (1988) 435:335-42. doi:10.1016/S0021-9673(01)82193-2

259. Miyamoto I, Nagase S. Purification and characterization of hyaluronic acid from the horny layer of guinea pigs. J Biochem (1984) 95:1331-6.

260. Reed RK, Lilja K, Laurent TC. Hyaluronan in the rat with special reference to the skin. Acta Physiol Scand (1988) 134:405-11. doi:10.1111/j.1748-1716. 1988.tb08508.x

261. Shimada E, Matsumura G. Molecular weight of hyaluronic acid from rabbit skin. J Biochem (1977) 81:79-91.

262. Dechert TA, Ducale AE, Ward SI, Yager DR. Hyaluronan in human acute and chronic dermal wounds. Wound Repair Regen (2006) 14:252-8. doi:10.1111/j. 1743-6109.2006.00119.x

263. Reed MJ, Damodarasamy M, Chan CK, Johnson MNR, Wight TN, Vernon RB. Cleavage of hyaluronan is impaired in aged dermal wounds. Matrix Biol (2013) 32:45-51. doi:10.1016/j.matbio.2012.09.004

264. West DC, Shaw DM, Lorenz P, Adzick NS, Longaker MT. Fibrotic healing of adult and late gestation fetal wounds correlates with increased hyaluronidase activity and removal of hyaluronan. Int J Biochem Cell Biol (1997) 29:201-10. doi:10.1016/S1357-2725(96)00133-1

265. Miyamoto I, Nagase S. Age-related changes in the molecular weight of hyaluronic acid from rat skin. Jikken Dobutsu (1984) 33:481-5.

266. Tobiishi M, Sayo T, Yoshida H, Kusaka A, Kawabata K, Sugiyama Y, et al. Changes in epidermal hyaluronan metabolism following UVB irradiation. $J$ Dermatol Sci (2011) 64:31-8. doi:10.1016/j.jdermsci.2011.06.006

267. Dahl LB, Dahl IM, Børresen AL. The molecular weight of sodium hyaluronate in amniotic fluid. Biochem Med Metab Biol (1986) 35:219-26. doi:10.1016/ 0885-4505(86)90077-0

268. Perry K, Haresign W, Wathes DC, Khalid M. Hyaluronan (HA) content, the ratio of HA fragments and the expression of CD44 in the ovine cervix vary with the stage of the oestrous cycle. Reproduction (2010) 140:133-41. doi:10.1530/REP-09-0424

269. Akgul Y, Holt R, Mummert M, Word A, Mahendroo M. Dynamic changes in cervical glycosaminoglycan composition during normal pregnancy and preterm birth. Endocrinology (2012) 153:3493-503. doi:10.1210/en.2011-1950

270. Ruscheinsky M, De la Motte C, Mahendroo M. Hyaluronan and its binding proteins during cervical ripening and parturition: dynamic changes in size, distribution and temporal sequence. Matrix Biol (2008) 27:487-97. doi:10. 1016/j.matbio.2008.01.010

271. Cordo-Russo R, Garcia MG, Barrientos G, Orsal AS, Viola M, Moschansky P, et al. Murine abortion is associated with enhanced hyaluronan expression and abnormal localization at the fetomaternal interface. Placenta (2009) 30:88-95. doi:10.1016/j.placenta.2008.10.013

272. Goulas A, Hatzichristou DG, Karakiulakis G, Mirtsou-Fidani V, Kalinderis A, Papakonstantinou E. Benign hyperplasia of the human prostate is associated with tissue enrichment in chondroitin sulphate of wide size distribution. Prostate (2000) 44:104-10. doi:10.1002/1097-0045(20000701)44: $2<104::$ AID-PROS2 $>3.0 . C O ; 2-6$ 
273. Lokeshwar VB, Rubinowicz D, Schroeder GL, Forgacs E, Minna JD, Block NL, et al. Stromal and epithelial expression of tumor markers hyaluronic acid and HYAL1 hyaluronidase in prostate cancer. J Biol Chem (2001) 276:11922-32. doi:10.1074/jbc.M008432200

274. Ng CK, Handley CJ, Preston BN, Robinson HC. The extracellular processing and catabolism of hyaluronan in cultured adult articular cartilage explants. Arch Biochem Biophys (1992) 298:70-9. doi:10.1016/0003-9861(92)90095-E

275. Sztrolovics R, Recklies AD, Roughley PJ, Mort JS. Hyaluronate degradation as an alternative mechanism for proteoglycan release from cartilage during interleukin-1beta-stimulated catabolism. Biochem J (2002) 362:473-9. doi:10. 1042/0264-6021:3620473

276. Holmes MW, Bayliss MT, Muir H. Hyaluronic acid in human articular cartilage. Age-related changes in content and size. Biochem J (1988) 250:435-41.

277. Coleman PJ, Scott D, Ray J, Mason RM, Levick JR. Hyaluronan secretion into the synovial cavity of rabbit knees and comparison with albumin turnover. $J$ Physiol (1997) 503(Pt 3):645-56. doi:10.1111/j.1469-7793.1997.645bg.x

278. Tulamo RM, Heiskanen T, Salonen M. Concentration and molecular weight distribution of hyaluronate in synovial fluid from clinically normal horses and horses with diseased joints. Am J Vet Res (1994) 55:710-5.

279. Band PA, Heeter J, Wisniewski H-G, Liublinska V, Pattanayak CW, Karia RJ, et al. Hyaluronan molecular weight distribution is associated with the risk of knee osteoarthritis progression. Osteoarthritis Cartilage (2014) 23:70-6. doi:10.1016/j.joca.2014.09.017

280. Barton KI, Ludwig TE, Achari Y, Shrive NG, Frank CB, Schmidt TA. Characterization of proteoglycan 4 and hyaluronan composition and lubrication function of ovine synovial fluid following knee surgery. J Orthop Res (2013) 31:1549-54. doi:10.1002/jor.22399

281. Wei L, Xiong H, Li B, Gong Z, Li J, Cai H, et al. Change of HA molecular size and boundary lubrication in synovial fluid of patients with temporomandibular disorders. J Oral Rehabil (2010) 37:271-7. doi:10.1111/j.1365-2842.2009. 02048.x

282. Schenck P, Schneider S, Miehlke R, Prehm P. Synthesis and degradation of hyaluronate by synovia from patients with rheumatoid arthritis. J Rheumatol (1995) 22:400-5.
283. Vasan NS, Saporito RA, Saraswathi S, Tesoriero JV, Manley S. Alterations of renal cortex and medullary glycosaminoglycans in aging dog kidney. Biochim Biophys Acta (1983) 760:197-205. doi:10.1016/0304-4165(83)90164-2

284. Declèves A-E, Caron N, Voisin V, Legrand A, Bouby N, Kultti A, et al. Synthesis and fragmentation of hyaluronan in renal ischaemia. Nephrol Dial Transplant (2012) 27:3771-81. doi:10.1093/ndt/gfs098

285. Lokeshwar VB, Obek C, Soloway MS, Block NL. Tumor-associated hyaluronic acid: a new sensitive and specific urine marker for bladder cancer. Cancer Res (1997) 57:773-7.

286. Purvis JA, Embery G, Oliver WM. Molecular size distribution of proteoglycans in human inflamed gingival tissue. Arch Oral Biol (1984) 29:513-9. doi:10. 1016/0003-9969(84)90072-4

287. Schmaus A, Klusmeier S, Rothley M, Dimmler A, Sipos B, Faller G, et al Accumulation of small hyaluronan oligosaccharides in tumour interstitial fluid correlates with lymphatic invasion and lymph node metastasis. $\mathrm{Br} J$ Cancer (2014) 111:559-67. doi:10.1038/bjc.2014.332

288. Lv H, Yu G, Sun L, Zhang Z, Zhao X, Chai W. Elevate level of glycosaminoglycans and altered sulfation pattern of chondroitin sulfate are associated with differentiation status and histological type of human primary hepatic carcinoma. Oncology (2007) 72:347-56. doi:10.1159/000113145

289. Kittlick PD, Engelmann D. The glycosaminoglycans in cultures of stimulated rat peritoneal macrophages. 2. Gel chromatographic studies and the behaviour of heparan sulfate. Exp Toxicol Pathol (1993) 45:87-92. doi:10.1016/ S0940-2993(11)80469-0

Conflict of Interest Statement: The authors declare that the research was conducted in the absence of any commercial or financial relationships that could be construed as a potential conflict of interest.

Copyright (C) 2015 Monslow, Govindaraju and Puré. This is an open-access article distributed under the terms of the Creative Commons Attribution License (CC BY). The use, distribution or reproduction in other forums is permitted, provided the original author(s) or licensor are credited and that the original publication in this journal is cited, in accordance with accepted academic practice. No use, distribution or reproduction is permitted which does not comply with these terms. 